\title{
الإصلاح السياسي عند الشيخ محمد رشيد رضا
}

\section{* محمد خروبات}

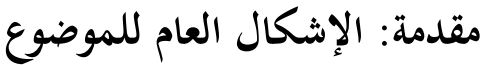

الحديث عن السياسة الشرعية عند رشيد رضا هو حديث يجلي حقيقة الإصلاح السياسي في فكره، كما ييجلي حقيقة السياسة الشرعية نفسها وذلك بإبراز خصائصها ومقوماتا ومقاصدها، ناهيك مِن مصادرها ومراحلها التاريخية، وهذا كله أو بعضه هو الذي يكشف عن مرتكزاتا في إصلاح أمور البشر، ومع رشيد رضا تتبلور مفاهيم هذه السياسة، ويتحرك مجال التنظير لأمورها العامة لا سيما الأحكام الشرعية العملية التي تنتظر الحياة بسرياها في واقع الأمة ... ومن هنا فالحديث في هذا الموضوع هو حديث عن كل شيء في دعوة الإصلاح عنده. فهو في فكره -رحمه الله- يذكره بمسميات متباينة لكنها لا تشير إلا إلى معنى واحد وهو المعنى الذي قصدناه بالسياسة الشرعية، فتارة يسميه بـ "الإصلاح الإسلامي والهدي المحمدي"1 وتارة أخرى يسميه بـ "الشرع الإسلامي والإصلاح المحمدي"، 2

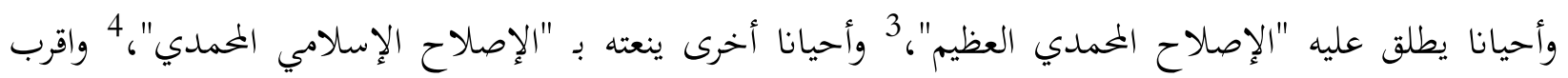
نعت إلى معنى مصطلحنا السابق هو النعت الذي استعمله في سياق كلامه عن العروة الوثقى التي استمد منها توجهه

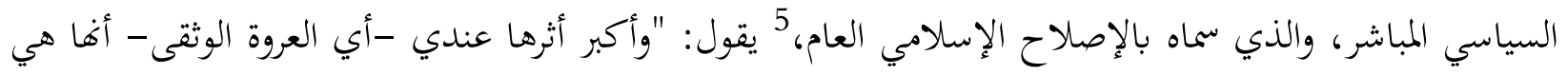
التي وجهت نفسي في الإصلاح الإسلامي العام". عاش رشيد رضا في فترة عصيبة من التاريخ، فالخلافة الإسلامية المركزية في إسطامبول تنهار شيئا فشيئا، والحكم العثماني قد تقهقر في الأقاليم والولايات، والاستعمار بدأ يعم العالم الإسلامي كله، ومحاولة ابتلاع أرض فلسطين واغتصابها تسير بخطى مخططة، وتخاذل الأمراء والولاة والحكام في القيام

دكتوراه دولة في علوم السنة النوية، جامعة القاضي عياض بمراكش 1998، أستاذ بكلية العلوم والآداب بنفس الجامعة.

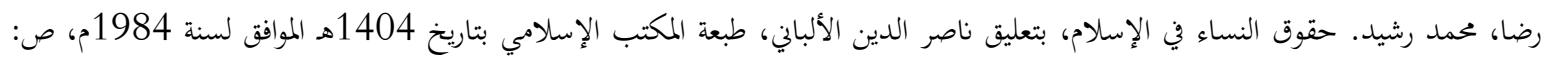

$$
\text { } 3
$$

5 5

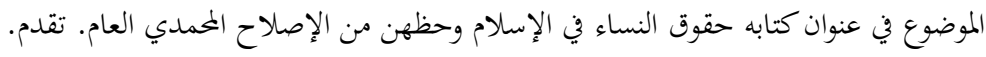


بالواجب قد عم وطم، وشاعت الدسائس والمؤامرات والخيانات، وتفاقم الوضع الداخلي بالحروب المستمرة التي غيرت من خريطة العالم الإسلامي ... أدت كل هذه العوامل إلى تبدد وحدة المسلمين وتشتت كلمتهم وتمزيق جغرافيتهم التي كانت موحدة، وقد تبع هذا تغيير في العقليات، وتغيير في أحكام الإسلام، هذا هو الجو الذي تنفس فيه رشيد رضا، وهو جو مكنه من أن يعي موقعه كمصلح، جو جعله يحس بأنه إنسان ما وجد في داخل هذه الأزمة العارمة إلا للإصلاح، إصلاح الوضع الداخلي لمصر في صلة الشعب بالسلطة المحلية، وفي صلة السلطة المحلية والشعب بالاستعمار الإنجليزي، وفي صلة مصر بأطرافها كاملة بالسلطة المركزية في الأستانة، وفي صلة مصر بكل الأقطار العربية التي تتحرك لأجل الانفصال كلبنان وسوريا وغيرها، ثم هناك قضايا أحزى تبدو أكثر أهمية في وححدة الصف ولم الشمل وهي التأليف بين مكونات المجتمع المصري كفئات النصارى والمعلمين في المدراس التبشيرية، وفئات طلاب العلم فيها، وفئات طلاب العلم الشرعي في الأزهر، والتوفيق بين الفئة المسلمة التركية المتمردة على السلطنة العثمانية والفئة العربية المسلمة التي يخلص بعضها للسلطنة وبعضها واقع في مهاوي الفئة التركية المتمردة، كل هذه قضايا باشرها من موقع الإصلاح، ولذلك ختم إحدى مقالاته في المنار بقوله تعالى من سورة هود (88): "إن أريد إلا الإصلاح ما استطعت، وما توفيقي إلا بالله".

\section{عناصر الموضوع: n (n}

سنحاول في هذا البحث أن نجلي حقيقة الإصلاح السياسي العام عند رشيد رضا الذي يتم وفق مرتكزات السياسة الشرعية التي هو شيخ فيها، وذلك من خلال بحث العناصر الآتية:

أولا: المؤهلات التي ساعدته على خوض غمار الإصلاح السياسي، وهذه المؤهلات تبدو واضحة في عمله السياسي، إذ بدونه يقع التقصير في هاته الجهة أو تلك.

ثانيا: بجلة المنار التي أطل بها على الواقع بعين الفحص والسبر، ودورها في إيصال كلمة "الإصلاح" إلى العقول والقلوب، وسيبقى رشيد رضا حيا في ساحة الإصلاح ما بقيت أفكاره الإصلاحية في بجلة المنار.

$$
6 \text { 6 المنار - الجلد } 12 \text { - ج } 12 \text { - يناير من سنة } 1910 \text { - مقال بعنوان: "العرب الترك: واعتصموا يجبل الله جميعا ولا تفرقوا". }
$$


ثالثا: موقعه من الظاهرة الإصلاحية العامة، فرشيد رضا هو امتداد طبيعي لجهود سابقة، وصوته في الإصلاح السياسي هو جزء من أصوات كثيرة ومتعددة الاتحاهات والمشارب، فلا بد من تحديد موقعه منها، وبيان مواقفه من تبايناتما واختلافاتا.

رابعا: ما السياسة الشرعية التي خاض غمار الإصلاح السياسي من منظورها؟ ما درجة علمه بها وفقهه فيها؟ كيف ذاد عن حوضها؟ وكيف عالج سلبيات العاملين في حقلها....؟ الجواب على هذه الأسئة يتضمنه هذا العنصر الذي يوضح المقاصد التي نرمي إليها في بحث الموضوع.

خامسا: شثملية الإصلاح عنده وعموميته، وهما عنصران من عناصر الشريعة الإسلامية، وخاصيتان من خصائصها، ومن خصائصها على الجملة العناية بالضرورات الخمس وهي في المحافظة على النفس والعقل والدين والنسل والمال، لذلك فجل القضايا التي دعا إليها في إصلاحه السياسي تدخل في الضرورات الخمس.

سادسا: السياسة التي تكلم فيها هي السياسية العامة، السياسة التي لا تستنني قضية من القضايا سواء أكانت محلية أم عالمية، داخلية أم خارجية.. غير أن الكلام في سياسة من هذا النوع يتطلب الحكمة والبصيرة، وهذه هي التي تضفي على الفكرة السياسية طابع التوازن.

سابعا: الموضوعات السياسية التي تكلم فيها، هي موضوعات تدل على صلته بالواقع، وحسن فقهه لقضاياه، فالموضوعات هي من صميم مشكلات الأمة في ذلك العصر مثل: الخلافة والشورى والثورة والاشتراكية، وهناك موضوعات أخرى كثيرة مثل الربا والتجارة والثروة والمال والدعوة إلى إصلاح التعليم واللغة العربية بما فيه وضع المدارس التبشيرية الحرة وقضية حقوق المرأة والصحافة... لكننا عدلنا عن الكلام فيها وابقينا على ما له صلة بـ"الإصلاح

\section{أولا : مؤهلاته في العمل السياسي:}

هناك مؤهلات ساعدت رشيد رضا على شق طريق الإصلاح العام، وأثرت في توجهه الفكري السياسي الشرعي، نذكر منها سبعة مؤهلات، وهي كالآتي: 
1. نسبه إلى آل البيت، فهو ينتمي إلى فرع الحسين بن علي بن أبي طالب، وكان يلقب نفسه ب"الحسيني"، ومعلوم أن أصول السياسة الشرعية إنما تمتد في سنة النبي عليه السلام وآل بيته الأطهار وصحابته الراشدين الأخيار، وهذه مزيّة انعكست على أسرة رشيد رضا التي اشتهرت بالرئاسة الدينية، فقد عهدت رئاسة بيت "آل الرضا" إلى والده علي الرضا، وهذا يجلي حقيقة أخرى وهي أن دعوته إلى الوحدة بين المذهبين الشيعي والسني إنما تمت من موقع جدارة انتسابه إلى أصول المذهبين.

2. ورثت أسرته -ابا عن جد- المنزلة الرفيعة، وحب الكرم وحسن الضيافة ولطافة الاستقبال، كما ورثت الهيبة والتقدير والاحترام والشرف عند السلاطين وولاة الأمور، فقد عاصر عصر السلطان العثماني وحيد الدين خان الذي كان يبعث إليه ببراءات، وهذه البراءات السلطانية تسلسلت من سلاطين بني عثمان إلى آل بيت رشيد رضا، كان آخرها البراءة السلطانية لوحيد الدين التي كانت قبل الحرب العامة. 7

3. العلم الشرعي الذي ضرب فيه بسهم وافر، فقد كان رمهه الله جامعا لعلوم الشريعة كلها، يجدر بنا أن نشبهه بعباقرة الإسلام الكبار من أمثال الشافعي والغزالي والسيوطي وابن تيمية وابن القيم ... ومعلوم أن من لا حظ له من علوم الإسلام الأساسية لا حظ له في إصلاح الأمة وتوفير رغباتما والتعبير عن حاجاتها الكبرى. 4. التقوى والورع والزهد وكرم النفس والعزة والإحجام عن المعاصي والإقدام على فعل الخير، لا نعلم -في حدود ما نعلم- أن أحدا غمزه في أخلاقه، أوتكلم في ورعه وتقواه.

5. التفتح والتسامح، وهما دعامتان أساسيتان للسياسة الشرعية، فأية سياسة ليست متفتحة هي سياسة مغلقة على نفسها، لا تجني من انغلاقها سوى العصبية والعرقية والمركزية، وأية سياسة ليست متفتحة فهي عدوانية وقاتلة، ولايمكن لأية سياسة هذا نوعها أن تحيى في الوجود، وإذا كانت هذه خاصية من خصائص السياسة الشرعية فهي خصلة أساسية في المفكر الإسلامي السياسي، وكان رضا على هذه الخصال، يبين لنا ذلك فيقول: "إني منذ دخلت سن التمييز أرى في دارنا وجهاء النصارى من طرابلس ولبنان، بل أرى فيها القسوس والرهبان، ولا سيما في أيام 
الأعياد، وارى الوالد يجاملهم كما يجامل من يزوره من الحكام ووجهاء المسلمين، ويذكر ما يعرف من محاسنهم في غيبتهم بكل إنصاف، وقد كان هذا من أسباب دعوتي إلى التساهل والوفاق وتعاون جميع أهالي البلاد". 8

6. سعة اطلاعه على المصادر الأجنبية، وهذه المصادر ما كان فيها مفيداً أقره وبنى حكمه عليه، وما كان مخالفا للمعقول والمنقول رده وعلق عليه، ${ }^{9}$ نذكر على سبيل المثال لا الحصر كتاب "الخلافة" لسير ويليام موير المطبوع مليك سنة 1924م وهو المصادف لسقوط الخلافة في تركيا، وكتاب "الإسلام"، للأستاذ أوجيست مولر، 10 وكتاب "حمد وخلفاؤه"، للأستاذ واشينجتون إيفرنج، 11 وغير ذلك، ومما هو جدير بالانتباه هو أنه كان يطالع بعضها باللغة

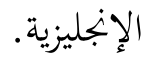

7. تأثره في الفكر السياسي برجلين كان لمما أثر كبير في حياته السياسية، هما:

أ. جمال الدين الأفغاني: (1838م - 1896م)، 12 هذا الرجل شغف برأيه وأحبه حبا شديدا وإن لم يره، ومعلوم أن توجه هذا الأخير هو التوجه السياسي الذي تمثل في المسائل الآتية: • بث الروح الإسلامية في الشرق حتى ينهض بثقافته وعلمه وتربيته وصفاء دينه وتنقية عقيدته من الخرافات، وتحرير أخلاقه مما علق بها من الرذائل والأمراض مع استعادة والعزة والكرامة. • إصلاح حال الدولة القائمة أوالثورة عليها إذا اقتضى الحال وإن كان الخيار الثاني هو الخيار المفضل خيار الثورة لأجل التغيير.

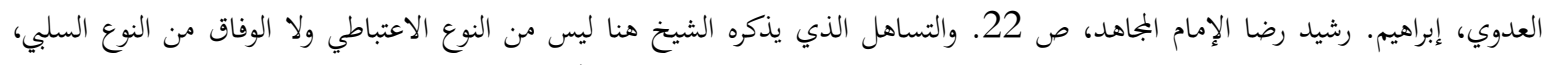

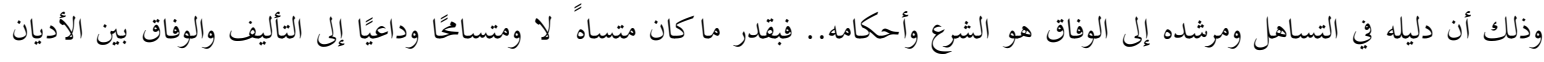

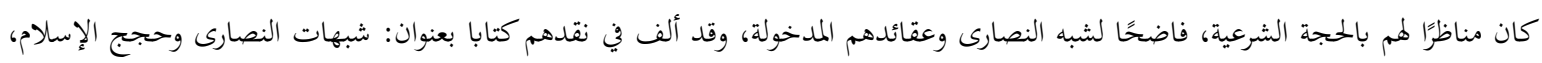

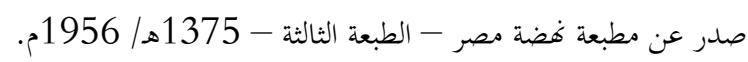

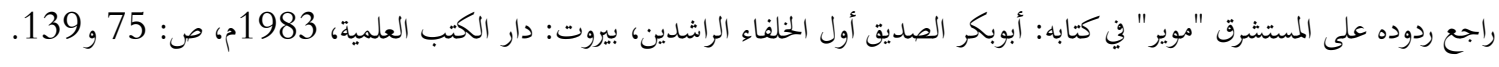
10 11 المصدر السابق.. ص: 22-23. الصعيدي، عبد المتعال. الجمدون في الإسلام: من القرن الأول إلى الرابع عشر، ترجمة الأفغاني، 373- القاهرة: مكتبة الأهرام، 1996 ص 
• مناهضة الاحتلال الأجنبي حتى يعود الاستقلال إلى الأقطار الشرقية، وعلى الدولة العببية أن ترتبط فيما بينها برباط ما لتتحدى الأخطار المحدّقة بها.

لقد عرف جمال الدين بالسياسة وبالعمل السياسي أكثر من أي اهتمام آخر، وقد وصفه بذلك تلميذه ورفيقه في الكفاح محمد عبده فقال: "وكان قادرا على النفع العظيم بالإفادة والتعليم، لكنه وجه كل عنايته إلى السياسة فضاع استعداده هذا".

ب. محمد عبده: (1845م - 1905م):15 يقولون إن توجه محمد عبده إنما هو توجه إلى الإصلاح التعليمي والتربوي فحسب، وهذا غير صحيح، فتوجهه إلى التربية والتعليم إنما جاء من الإصلاح السياسي 16 الذي قضى فيه عمرا طويلا بصحبة شيخه الأفغاني، وكان يصدر معه مجلة "العروة الوثقى" التي تضمنت دعوات كثيرة إلى الإصلاح السياسي وعن طريقها تعرف رشيد رضا على حقيقة هذا الإصلاح، غير أنه لم يشرع فيه عمليا إلا بعد موت شيخه محمد عبده الذي غير توجهه الإصلاحي في المراحل الأخيرة من عمره، وبالضبط لما دخل القاهرة عام 1883م. كان الإصلاح السياسي عند "عبده" من الأولويات التي رسخها فيه الأفغاني، وكان يدخل في مجالين الأول هو الاشتراك في الثورة العرابية ودعمها، بل كان من كبار زعمائها، وبسببها كان من المغضوب عليهم، غير أن الخحيوي صفح عنه لما عاد إلى مصر لما اتصف به من الحلم وكرم الخلق، والمجال الثاني هو محاربة الاستعمار الإنجليزي، وهذه المحاربة تتمثل في التحريض السياسي ضد وجوده فوق الأراضي الإسلامية، وكانت العروة الوثقى منبرا لكل هذه

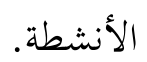

لكنه وبعد تجربة مريرة عاشها غيّر خطه الإصلاحي جملة واحدة حيث رأى ما هو أجدر بالإصلاح وأنفع وهو الإصلاح التعليمي والتربوي، وهناك قال قولته المشهورة (أعوذ بالله من السياسة، ومن لفظ السياسة، ومن معنى السياسة، ومن كل حرف يلفظ من كلمة السياسة، ومن كل خيال يخطر في بالي من السياسة، ومن كل أرض تذكر

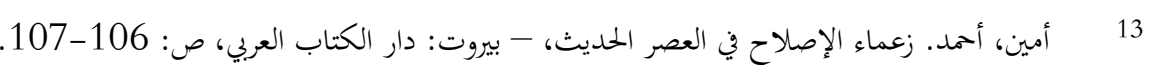

$$
\begin{aligned}
& 14 \text { 15 } 14 \\
& 15
\end{aligned}
$$

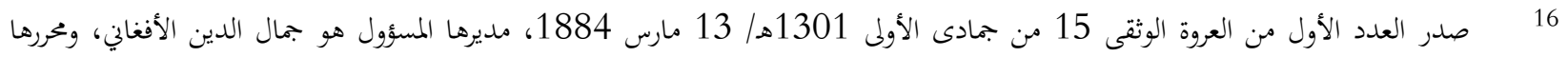

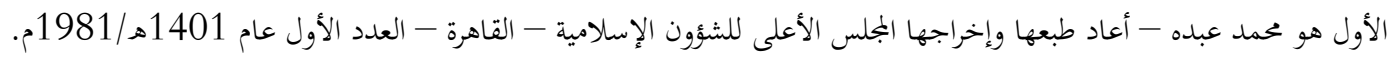


فيها السياسة، ومن كل شخص يتكلم أويتعلم السياسة، أويحب أو يعقل في السياسة، ومن ساس ويسوس، وسائس

كانت هذه جملة من المؤهلات ساعدت رشيد رضا بشكل أو بآخر على ولوج العمل الإصلاحي في صيغته

السياسية التي تنبني على شرع الإسلام، ولم تكن فكرته الإصلاحية سوى مظهرٍ من مظاهر تأثير الواقع الذي عاش فيه، غير أن هذا التأثر لم يصل إلى حد الانجراف مع سلبيات الواقع ومشكلاته، بل وقف منه الموقف الذي كان ملائما ومتلائما مع منحاه الإسلامي، وطبعي جدا أن ينتظر المسلمون من رجل كهذا إنارة الطريق المظلمة بالجهل والظلم والفساد، وتوجيهُم نهوسبل الفلاح والرشاد، ويمكن للباحث -لأي باحث كان- أن يقر بحقيقة واضحة وهي أن الشيخ رحمه الله كان على اطلاع تام بمختلف التيارات الفكرية والأنظمة السياسية القائمة، واعيا برغبات الأمة نحو الخير والسعادة.. ومما زاد من توسيع الفقه السياسي أنه كان على دراية بطرق الفساد وأوجه الضلال التي استشرت سمومها في جسم الأمة.. لم لا يكون في مستوى الفحص والمعالجة وهو الحائز على العقاقير المضادة لمذه السموم من صيدلية الإسلام العامرة "ومن يؤت الحكمة فقد أوتي خيراً كثيراً". (البقرة: 269)

ثانيا: المنار ودورها في الإصلاح السياسي:

في الوقت الذي عاد فيه محمد عبده إلى مصر بنفس جديد في الإصلاح، وبطريقة خختلفة عن المرحلة السابقة نرى تلميذه رشيد رضا يعقد العزم على الهجرة إلى مصر ليؤسس مجلة يبدأ من خلالها إصلاحاته العامة، هكذا دخل رضا مصر قادما إليها من بيروت بتاريخ 8 رجب من سنة 1315هـ الموافق ل3 يناير من عام 1898م، وهذا تاريخ ملائم لبداية العمل السياسي حيث صدر في السنة نفسها -في 15 مارس- العدد الأول من بجلة "المنار"بمباركة محمد عبده وبمساعدته، ومكثت من هذا التاريخ إلى سنة 1905م تولي أمرها إلى "الإصلاح الديني" لأن الأستاذ الإمام

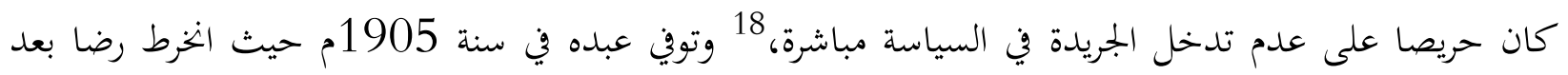
وفاته في العمل السياسي العام، ومما زاد من تقوية عزيمته أن صدى حركة (تركيا الفتاة) بدأ يتسع إلى الخارج، فبادر

$$
18 \text { } 17
$$

18 
رضا إلى تأسيس جمعية (الشورى العثمانية) التي مكنته من إصدار مقالات في الاستبداد وسياسة السلطان عبد الحميد وحكم الشورى وطرق إصلاح الدولة العثمانية...

عمرت المنار عمرا يناهز سبعا وثلاثين سنة، من سنة 1898م إلى عام 1935م، وهو عمر ظهرت فيه أحداث سياسية جسام كان أكبرها اهيار الإمبراطورية العثمانية والقضاء على خلافتها، وظهور الثورة البلشفية الاشتراكية الشيوعية في روسيا التي قضت على النظام القيصري المستبد والمعتدي على حدود الإمبراطورية الإسلامية، وما جرى بين حركة نجد وحركة الحجاز حول تولي الزعامة على مقدسات المسلمين وتدخل الاستعمار الإنجليزي في المنطقة، وبروز ظاهرة الانفصال التي استفحلت بشكل ذريع في العالم العربي وي شرق أوربا، وظهور ظاهرة القومية العربية التي تنظر لمستقبل الدولة الوطنية في العالم الإسلامي من منظور الصيغة العلمانية التي أسس دعائمها مصطفى كمال أتاتورك....19 وهذا كله كان يخلف في المجتمع الإسلامي آفات أخلاقية خطيرة، وعللا وأمراضا فتاكة كلها كانت تتجاوب مع الوضع السياسي العام، كانت مجلة المنار تواكب هذه المشكلات وتتصدى لها بروح علمية وإيمانية وجهادية عالية، ويخطئ من ينظر إليها على أها مجلة دينية إصلاحية فقط، بل هي -علاوة على ذلك- فكرية سياسية ثائرة على الوضع، تمارس السياسة بمعناها العام ومن منظور السياسة الشرعية التي دخلها رضا من أفق الفهم الفقهي المتميز، وهي بخلاف (العروة الوثقى)، لأن العروة الوثقى كانت تخاطب الشعب من الخنارج في حين كانت المنار تخاطبه من وسط مشكلاته الحية والحيوية، ومما زاد من تألقها أن صاحبها كان عالما بشؤون جزيرة العرب وشؤون أمرائها،وعارفا بظاهرة الحركات العربية بأحواها وأحزاجها وجمعياها، كما كان واسع المعرفة بأحوال الدولة العلية وما يراد لها من الداخل والخارج، وهذا كله تدل عليه مقالات رشيد رضا في المجلة، والواقع أن مجلة "المنار" هي رشيد رضا، فكل فكره الإصلاحي هو موجود في هذه المجلة، وكل ما ألفه من كتب مستقلة إنما يوجد كثيره أوبعضه في المنار، 20 والسبب في ذلك أن المنار ارتبطت بعمر صاحبها فقد توقفت لما توقفت حياته، والفضل يرجع إليه في أنه بهذه المجلة وقف صومعة عالية تخترق حجب السماء الملبدة بغيوم التعتيم الإعلامي والتمويه على الحقائق، وقد وقفت المنار في وجه الصحافة التركية الداعية إلى الانفصال عن العرب وتمجيد القانون الأوربي وإيقاف الاستبداد السلطاني، كما

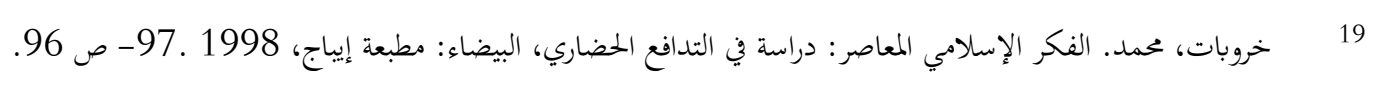

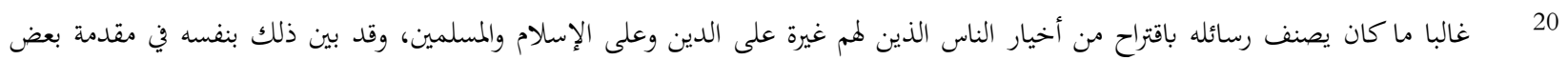

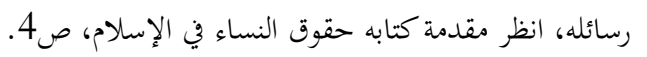


كانت جرائد أخرى في البلاد العربية المشهورة بحرية الصحافة كمصر وسورية تحرك أقلامها لهذا الغرض، كانت المنار تقف حائلا أمام كل تلك الدعاوى والأقوال المزيفة، لكن بالحجة والدليل وبصيغة مرنة مقبولة حتى وصفت بأها "لسان حال الإصلاحيين المعتدلين".

\section{ثالثا: موقعه من الظاهرة الإصلاحية العامة}

لم يكن رشيد رضا هو الذي يتكلم وحده عن الوضع السياسي العام للأمة، بل راح المثقفون يتكلمون من مختلف الاتحاهات، فالمسيحيون العرب ينظرون للحالة السياسية العامة والقوميون العرب من المسلمين يتكلمون، والأتراك يخططون لمشروع القومية التركية التي اتخذت من العلمانية طريقا سياسيا جديدا لها، والدولة الوطنية تتكلم عن التحرر بطريقتها وبأسلوبها وبمقاصدها الخاصة التي تحفظ لها البقاء والاستمرارية، والمستشرقون يحللون الوضع بطريقتهم الاستعلائية وبمنهجهم الانتقائي المشوه وكل يتكلم، أما المخلصون من أبناء الأمة، الراغبون في الإصلاح على الطريقة الشرعية مثل الأفغاني وعبده ورضا وأحمد خان في الهند فلهم تصور مختلف للوضع.

يمكن القول أن مرحلة ما قبل سنة 1908م كانت فيها آراء الشيخ رشيد رضا تتماشى مع آراء محمد عبده ومواقفه، وهي: مهادنة الاستعمار والانتفاع بعطياته المادية والحضارية، وهذا الموقف يشكل نقطة افتراق عن الخط السياسي الإصلاحي الذي رسمه جمال الدين الأفغاني من قبل، دلك أن مشروع هذا الأخير كان مشروعا سياسيا إصلاحيا بالدرجة الأولى، أما رشيد رضا فقد كانت نظرته إلى الإصلاح نظرة عامة، نظرة تأخذ بعين الاعتبار حتى النظرات الإصلاحية الأخرى، نظرة تستنبط الإيجابي من تلك المواقف وتترك السلبي، وقد مكنته هذه الطريقة من أن يقف على حقيقة الدعوات الإصلاحية سواء في مصر أوفي خارجها، يدلنا على ذلك الموازنات الني كان يعقدها بين الجهود الإصلاحية لرواد الإصلاح السياسي في عصره كموازنته بين جمال الدين الأفغاني والسيد أحمد خان في الهند 22 وبين هذا الأخير ومحمد عبده، 23 كل ذلك لأجل اختيار طريق سليم وصحيح، وهو الطريق المركب من إيجابيات

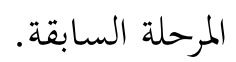

$$
\begin{aligned}
& 21 \text { كوثراني، وجيه. مختارات سياسية من مجلة المنار، بيروت: دار الطليعة، 1980، ص } 36 . \\
& 22 \\
& 23
\end{aligned}
$$


إن العمل السياسي هو عمل غير كاف في الإصلاح إذ لا بد من إصلاح التعليم والتربية والتوجه إلى إصلاح عيوب المجتمع وهذه القضايا أهمل منها الأفغاني الشيء الكثير، في حين كان أحمد خان في الهند يوازن في دعوته بين السياسي والتربوي والثقافي والتعليمي وحتى الاجتماعي، لذلك فاق جمال الدين الأفغاني في هذه الأمور وإنغاقه جمال الدين في السياسة، وأعتقد أن عزوف محمد عبده عن السياسة في آخر أيامه يأتي من كونه أحس بنقطة الضعف في دعوتما (هو والأفغاني) طوال تلك السنين، وهو أن المجتمع الإسلامي في حاجة إلى إصلاح تعليمي وتربوي أكثر، وأن الإفراط في العمل السياسي يمكن أن يحرق أوراق الإصلاح كلها لما فيه من المخاطرة بالنفس والنفيس، وفعلا فقد كانت هاية جمال الدين الأفغاني على هذه الصورة تماما، وكادت الصورة نفسها أن توقف مسار عبده لولا أنه غير المنهج حيث بدأ ينظر إلى الاستعمار نظرة أخرى غير الحرب والجفاء اللذين لن يعطيا شيئا. يمكن أن يكون هناك تعاون جاد ومسؤول يعود على أفراد المجتمع الإسلامي بالنفع، وهنا يتحول (الاستعمار) إلى أداة مسخرة في الإصلاح، لقد أدرك عبده بنظرته التي خضعت لتجارب عديدة أن الحرب والثورة على الاستبداد الداخلي والخارجي أداها الشعب، جميع أفراد الشعب، وهؤلاء ليسوا في مستوى من العلم والوعي والتربية التي تؤهلهم لخوض غمار الثورة لتغيير الوضع، فلا بد إذا من تربيتهم وتوعيتهم وتنوير فكرهم... كان هذا هو السبب الذي جعل الشيخ رضا يميل ميلة عظيمة عن السياسة ويصدر في حقها ما قد رأيتَ.

لماذا شاطر رشيد رضا محمد عبده في عزوفه عن السياسة؟ وهل السياسة التي أدار رشيد رضا ظهره لها بصحبة شيخه هي كل السياسة أم هو عزوف عن جزء منها فقط؟

سؤال وجيه جدا، وجوابه أن رشيد رضا في هذه المرحلة كان حديث العهد بصحبة محمد عبده، وكان محمد عبده هو الموجه والمدير لأفكار الإصلاح، وهذا يبين أن رضا كان تابعا لشيخه في كل شيء، هذا من جهة، ومن جهة أخرى فإن السياسة التي عدلا عنها هي السياسة التي تتعلق بقضية الاستعمار وصلته بالنواحي الاقتصادية والاجتماعية والثقافية داخل البلاد، وكذلك في صلته بالسلطة الحاكمة، فكأن رضا يريد أن يفسح المجال للسلطان ليقوم بمهمته، وهي المهمة التي لا يمكن لأحد أن يقوم بها وذلك لسبب واحد هو أها أعلا من الجميع، وحتى الاستعمار ليس مهيئا لأن يتحاور ويتذاكر مع أي طرف كان إلا أن يأتي من جهة السلطان أو من قبل جهة لها وزن سياسي وشعبي، وكل محاولة تخج عن هذا الإطار فإنها عرضة للسحق، إما من جهة السلطة الداخلية التي لا تفيد 
بمشاركة أحد في محاورتا مع الاستعمار، وإما من جهة الاستعمار الذي لا يسمح لأي أحد أن يتولى الوصاية على الشعب وعلى السلطة المحلية، وكيف يسمح وهو لا يعترف حتى بشرعية السلطة القائمة في البلاد، لذلك كان رضا يرى أن الإصلاح "لا يمكن القيام به إلا باتقاء السياسة فيه، واجتناب مقاومة السلطة له، ويجعل مداره على تربية النفوس بالدين، وترقية شأن البلاد الاجتماعي والاقتصادي وترك السياسة لأهلها".

\section{ما السياسة التي تركها رضا لأهلها؟}

لا شك أفا السياسة التي تخص أهلها، السياسة التي لا مدخل لرضا ولغير رضا فيها، لكن هناك سياسة أخرى يعرفها رضا ويجيدها وهي السياسة التي يتوجب عليه أن يقوم بما، ويدعو الناس من خلالها ويباشر الإصلاح من موقعها، هذه السياسة هي السياسة الشرعية التي جاء بها دين الإسلام، السياسة التي تصلح للبلاد والعباد، وبدوها يقع الخلل ويكصل الفساد، هذا النوع من السياسة لا يجيده اللورد كرومر ولا تعرفه السلطات الاستعمارية البتة، كما أن السلطة القائمة وإن كانت تعرفه -بحكم انتمائها إلى الإسلام- فإنها تحبذ الدعوة إليه لا العمل به.... وهذا فيه إجابة واضحة للذين عاينوا إصلاح رضا من مواقع خاصة، أولئك الذين رأوا في نبذه للسياسة واعترافه بحالة الاستعمار

$$
\text { عملية احتواء وتوافق، واتكالية مع استقبال مريح (للغرب الرأسمالي في الشرق العربي). } 25
$$

كان رشيد رضا يدرك أطماع الغرب ومشاريعه في المنطقة، وأيديولوجياته التي يريد اكتساح القيم الإسلامية بها، كانت طموحات الاستعمار تظهر لرضا في مسألتين الأولى في مصالحه السياسية والاقتصادية والثقافية التي يجنيها من تواجده في المنطقة، وإدراك هذه الرغبة، والوقوف عند حدودها يتطلب الوعي بحالة العالم في ذلك الوقت، أي أن يكون المرء على حالة من الوعي السياسي العالمي، وكان رضا على معرفة تامة وجيدة بذلك. أما المسألة الثانية فتتعلق بمتطلبات أحوال الداخل، وتحقيق رغبات المستعمرين مثل التعمير والتحضير والتمدن وبناء المدارس والمستشفيات والإصلاحات الاجتماعية الداخلية.... وكان رشيد رضا يدرك أن هذه الإنجازات التي يقوم بها الاستعمار ما هي إلا وسيلة لتحقيق الرغبة الأولى.

حيال هاتين المسألتين انقسمت الفئات الداعية إلى الإصلاح إلى أربع طبقات:

$$
\begin{aligned}
& 24 \text { 2 } 25 \\
& 25 \text { كوثراني، وجيه. مصدر سابق ص } 26 \text { وص } 33 \text { و والخاتمة. }
\end{aligned}
$$


الطبقة الأولى: تمثلها السلطات الاستعمارية، وهذه السلطة لها حكم معين، وهي تباشر إصلاحا من نوع معين النوع الذي يضمن للغرب مصالحه وأمنه ووجوده على أرض الواقع.

الطبقة الثانية: وهي الطبقة التي انبهرت بالتقدم الحضاري للغرب، غالبيتهم تعلموا في المدارس الحديثة التي أنشأقةا الإقامة العامة، هؤلاء كان رشيد رضا يسميهم بـ "المتفرنجين" لا تربطهم بتراثهم أي رابط عاطفي، بل كثير منهم بجاجهل جهالً تاماً حقيقة "الإسلام" و"الشريعة الإسلامية" وحقيقة "التراث والتحرر"، ويرجع تكوين تيار الفكر الليبرالي العلماني الذي تمثل أيديولوجية الغرب إلى هذه الفئة، فراح يقدم في ساحة الإصلاح عنصر الاندماج مع الأفكار السياسية الوضعية التي أنتجها الغرب، بل ناضل من أجل تبنيها وترسيخها ومحاربة ما يهول دوها، نذكر من هؤلاء مثلا فارس نمر وفرح أنطوان وشبلي شميل والقائمة تطول، وقد اتسع رواد هذا المذهب في السنوات التي تلت هذه المرحلة.

الطبقة الثالثة: وهي طبقة السلطة الحاكمة في البلاد، سلطة لها رغبة في استمرار الحكم على الطريقة الاستبدادية، وهذا كله لأجل بقاء السيد الحاكم الذي يرعى مصالحه ومصالح شبكة من أدعياء الإصلاح النفعيين، أولئك الذين يرفهو ن أنفسهم في مقابل إفقار شعوبم، ولذه الطبقة مطامح وأيديولوجيات معينة فهي تتخذ من

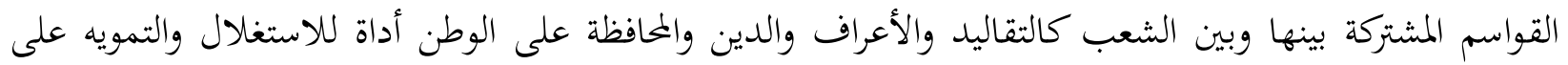
الرعية، ومن خلال تسييرها للشؤون الداخلية عبر الوظائف الرسمية التي تحت سيادتا تكرس مفاهيم معينة يراد لها أن تكون ثابتة ومركزية.. بل غالبا ما تضحي بمصالح الشعب لفائدة مصالح الاستعمار، يدلنا على ذلك أفا كانت سببا في دخول الاستعمار، إذ أها كثيرا ما كانت تقترض لترفيه نفسها وحين تعجز عن إرجاع الديون تتدخل السلطات الأجنبية في البلد متخذة من ذلك ذريعة، وأعتقد أنه بهذه الصورة دخلت فرنسا وإنجلترا إلى مصر، كما دخل الاستعمار إلى بلدان إسلامية أخرى بالصورة نفسها.

الطبقة الرابعة: إذا نحن عرضنا سلبيات الطوائف السابقة تبين لنا أن الإصلاح الحقيقي -(الإصلاح العظيم) كما يسميه رشيد رضا- لا يمكن أن يتم من خلالما ومن خلالما وحدها، فنوايا الاستعمار واضحة تدل عليه ممارساته النظرية والعملية في البلاد، ومصالح الطبقة الحاكمة -والتي لها تحكم نسبي في الوضع- لا تعكس الإصلاح المرتقب، أما الطائفة الحليفة للغرب فالإصلاح معها يذوب وينحل، لأهما -كما يقول-: "لا قيمة لها في نفوس السواد الأعظم 
لبعدهم عن الدين".26 غير أن الجدل كان حادا بين فئتين: الأولى فئة ترى أن الإصلاح السياسي يأتي من جهة الطبقة الحاكمة في البلاد، فالإصلاح لا تقوم له قائمة في نظرهم إلا بالاعتماد على الأمراء والسلاطين والحكام. والثانية فئة ترى أن الإصلاح السياسي ينبثق من القاعدة لا من القمة، لأن القمة في نظرهم هي سبب الفساد فلا يعول عليها في الإصلاح.

غير أن رشيد رضا رأى أن يدير وجهه عن هذا الخلاف واختار التوفيق حيث رأى أن إصلاح الحكام لا يكون إلا إذا كانت الأمة متعلمة ومهذبة، وإذا قذذبت الأمة وتعلمت تذذبت جميع فصائل المجتمع ومكوناته بما فيه الحكام، لذلك فهو يدير وجهه جهة الذين شعروا بمصاب المسلمين ليقوموا بواجبهم أحسن قيام، بمن فيهم رجال الإصلاح، وهؤلاء هم أهل الطائفة الرابعة، ثم يتوجه إلى رجال الحكومة فيتهمهم بالإثراء غير المشروع على حساب الشعب الفقير، ودعوته إليهم أن يقوموا بمحاربة الرشوة والفساد المسيطرين على الدوائر الحكومية، وطالب الحكومات وحث الجمعيات على القيام بأعمال البر والإحسان، 27 يقول في عبارة جامعة: "لا بقاء مع ظلم وفساد، ولا عدل مع استبداد، ولا هلاك مع إصلاح، ولا إصلاح للدولة إلا بصلاح الأمة، ولا صلاح لأمة إلا إذا كان فيها بقية من أولي الرأي والعزم، يأمرون بالصلاح وينهون عن الفساد في الأرض، ولا تأثير للأمر والنهي إلا بإماع الأمر وإحكام الرأي، ولا يفيد الإحكام والإجماع مع مراعاة سنن الاجتماع لاختلاف استعداد الأقوام باختلاف أحوال الزمان والمكان، وزماننا هذا هو زمان الجماعات العلمية والأدبية والسياسية، والشركات الزراعية والصناعية والتجارية، ومتى ملكت الأمة بالجمعيات أمورها المعنوية وبالشركات أمورها المادية كانت جديرة بأن تقوم أمر حكومتها وتقيمها على صراط

إن أفضل طريق للإصلاح هو الإصلاح السياسي الذي تتعاون فيه القمة مع القاعدة حيث يشترك الجميع في إصلاح واحد، لأنه متى كان الإصلاح في جهة واحدة كان ناقصا، "فالحكومة تملك القدرة على إلزام الأمة بالإصلاحات، وصلاح الأمة يؤدي إلى صلاح الحكومة لأن الصالح لا يختار إلا مثله ". 29

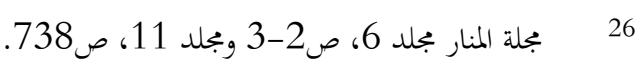

$$
\begin{aligned}
& 27 \text { } 28 \\
& 28 \text { 2 } \\
& 29
\end{aligned}
$$


وإذا كان رشيد رضا وقف بين الفئة الموالية للحكومة والفئة المعادية لما والموالية للشعب على النحو الذي عرضنا فقد وجدناه يوفق بين فئتين إصلاحيتين مختلفتين: إحداهما موالية للاستعمار وللدولة الوطنية الغربية وتريد أن تجري الأمور على ما عليه حالة الدولة في الغرب؛ والثانية تعادي الغرب مطلقا، وتريد من الإصلاح أن يكون من الداخل، يسير وفق الخصوصية والذاتية والمقومات والثوابت، وغالبية هؤلاء هم من العامة.

حاول رشيد رضا أن يجمع بين الرأيين في رأي واحد تمثله طائفة واحدة أكد على ضرورة وجودها في حل الخلاف فقال: "لا بد من حزب وسط بين العامة وبين المتفرنجين يكون له جانب إلى النظام والمدنية وجانب إلى الدين النقي"، 30 فجانب "النظام والمدنية" يتمثل في إدخال النظم الغربية، وأساليب الحضارة وطرق التسيير ووسائل التنظيم في الإصلاح الإداري، فالإسلام والحضارة صديقان يتفقان ولا يختلفان، 31 وجانب "الدين النقي" يتمثل في الالتزام بالشريعة الإسلامية في الحكم السياسي، وتسيير شؤون العباد بها، فإحلالها في واقع الأمة هو حياتا، وإلغاؤها هو إبعاد للإسلام عن أرض الواقع.

هكذا يرتفع صوت رشيد رضا في سماء الإصلاح العام ليكون خير ممثل لهذه الطائفة التي أسس لها جمال الدين وأتمها محمد عبده، وأكملت مع رشيد رضا، طائفة تتلاف سلبيات الدعوات الأخرى لتعمل وفق الإيجابيات، ومن إيجابياها: الاعتدال والتوازن والمرونة والعلم والتخطيط، وهي كلها عناصر قابلة لأن تبحث من خلال جهود رشيد رضا في الإصلاح، لوجمعت وبكثت لبرهنت على أن رشيد رضا يمثل في طبقته هاته التيار السياسي العقلاني الشرعي.

\section{رابعا: فقهه السياسي الشرعي:

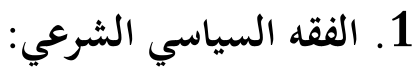

الفقه السياسي الشرعي هو عمدة السياسة الشرعية، والسياسة الشرعية تقوم على حسن فهم حقيقة الشرع وحسن إنزاله على الواقع، ثم حسن الإدراك لما يترتب على هذا الإنزال من مآلات وقضايا، 32 وهذا كله لا يخزج عن "إقامة الحق والعدل، وقيام الناس بالقسط، فأي طريق استخرج به الحق ومعرفة العدل وجب الحكم بموجبها

$$
31 \text { 31 } 31 \text { المنار، مجلد } 93 \text { - الفكر الإسلامي المعاصر، مصدر سابق. 286-287. }
$$


ومقتضاها، والطرق أسباب ووسائل لا تراد لذواتما وإنما المراد غايتها التي هي المقاصد، ولكن نبه بما شرعه من الطرق على أسباهما وأمثاها، ولن بحد طريقا من الطرق المثبتة للحق إلا وهي شرعة وسبيل للدلالة عليها، وهل يظن بالشريعة الكاملة خلاف ذلك؟".

والسياسة الشرعية مصطلح جرى استعماله عند أئمة الإسلام، وقد صنفوا فيه مصنفات كثيرة، 34 وأقوى من حاول تحديد معناه تحديدا عاما العلامة ابن قيم الجوزية في مؤلفه "إعلام الموقعين" فقد وضع فصلا بعنوان: "كلام الإمام أحمد في السياسة الشرعية" ساق فيه مجموعات روايات للإمام تخص بعض الأحكام الفقهية كنفي المخنث أوحبسه، وإقامة الحد على شرب الخمر في رمضان، ومعاقبة من سب الصحابة ومن أسلم وتحته أختان أجبر على إحداهن، ثم انتقل إلى الإمام الشافعي فذكر أشياء من فقهه في مثل هذه المسائل مثل جواز وطء الرجل المرأة ليلة الزفاف وإن لم يرها ولم يشهد عدلان على أها امرأته بناء على القرائن، وذكر في مثل هذه الأمور مجموعة من الأحكام ليقول في ختام ذلك: "وهل السياسة الشرعية إلا من هذا الباب..."35 ... هكذا تكون السياسة الشرعية التي اشتغل بها رشيد رضا إلا من هذا الباب، فهي لا تبتعد عن روح المعنى الذي حدده ابن القيم وغيره من أئمة الإسلام، غير أن شكلها ومظهرها يختلف باختلاف أقضيتها في جريان العصور، وكانت مشكلات العصر وتفاقم أزماته السياسية سببا في تكوين الفكرة السياسية الشرعية عند رشيد رضا.

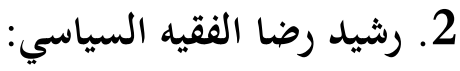

من شروط الكلام بالسياسة الشرعية، ومن شروط التأليف والتصنيف فيها، وفي القضايا التي تمس واقع الأمة من خلالها أن يكون صاحبها فقيها حق الفقه، وتدلنا المقالات التي كتبها رشيد رضا، وعالج فيها قضايا عامة ومختلفة أنه كان فقيها له اطلاع واسع 36 على كتب الفقه وله معرفة جيدة بحقيقة المذاهب الفقهية المتبوعة وغير المتبوعة، وله

$$
\begin{aligned}
& 33 \text { 3 ابن قيم الجوزية. إعلام الموقعين عن رب العالمين، بيروت: دار الفكر، 1977، تحقيق محي الدين عبد الحميد. }
\end{aligned}
$$

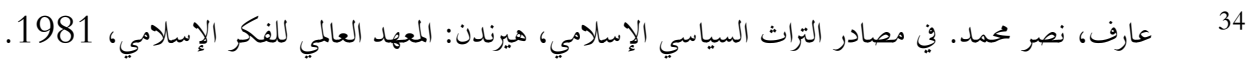

$$
\begin{aligned}
& 35
\end{aligned}
$$

36 أنظر كتاب الوحدة الإسلامية والوحدة الدينية، مجموعة مقالات صدرت في المنار، المجلد الثالث والرابع والسادس، تعالج قضايا عامة في الفقه

$$
\text { ال. السياسي الشرعي من ذلك مثلا: }
$$

أ. محاورات المصلح والمقلد في مسألة الاجتهاد والتقليد والوحدة الإسلامية 
إلمام واسع بقواعد علم أصول الفقه والمقاصد الشرعية، وكان عالما بكتب الأحكام الفقهية من القرآن والسنة النبوية، كما كان عالما باجتهادات السلف من الصحابة والتابعين ومن تبعهم، وقد مكنته هذه المعرفة الواسعة من أن يعمل بالفقه السياسي الشرعي عملا تصاحبه النظرة العلمية الواعية بأن هذا الفقه أصبح جسدا بلا روح، فجسده قائم في المراجع والمصادر والأصول لكن روحه ضاعت تماما بسبب تعطيل العمل بالشريعة الإسلامية في الحياة العامة للبلاد الإسلامية، كما أنه كان يعي أن كثيرا من مفكري عصره من القوميين والغربيين يرددون شبهة استشراقية مفضوحة مفادها أن الشريعة الإسلامية إنما استمدت كثير من بنودها من القوانين الرومانية، وهذا فيه تضليل للشعوب العربية والإسلامية التي تعاني من الجهل الفظيع بسبب أميتها وبعدها عن الإسلام، وهي بلا شك عون للاستعمار على تحكيم ربقته في سياسات المسلمين بالسياسات الغربية الوارثة الطبيعية للقوانين الرومانية، فكان لا بد لرشيد رضا أن يدعوعلماء الأمة وشباهما إلى الاطلاع على ذخيرقم الحية في الفقه الإسلامي، ذخيرة توارثوها خلفا عن سلف وهي حجة عليهم في تاريخهم وحضارقم وواقعهم، يقول محفزا: "أن يعلم من أدلتهم ومداركهم ما هو مستند إلى نصوص الكتاب والسنة القطعية أو الظنية، وما مستنده القياس أو الاستنباط من القواعد العامة أو الخاصة بمذهب دون مذهب المصالح عند المالكية وغيرهم والاستحسان عند الحنفية، وبهذا يعلم غلط من زعم أن المسلمين استمدوا أحكام

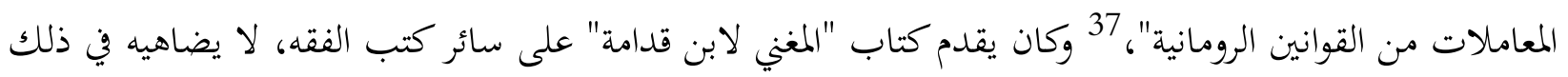
سوى كتاب "المحلى لابن حزم" الذي كان يعتبر صاحبه مجددا للفقه الإسلامي مثل العز بن عبد السلام، ومع هذه الدرجة التي حظي بها المحلى عند رشيد رضا فإن المغني حظي بثناءات مطلقة عنده لدرجة أنه قال مرة: "وإذا يسر الله تعالى لكتاب المغني من يطبعه فأنا أموت آمنا على الفقه الإسلامي أن يموت"، 38 وقد بسط بين يدي هذا التقديم مبررات علمية كثيرة أهمها أن ابن قدامة لخص مذاهب فقهاء المسلمين المجتهدين بأدلتها من أمهات الأحكام ومهمات المسائل، بعيدا عن التعصب في كل ترجيح، وبعيدا عن تكلف الطعن على أهل الجمود من المقلدين، هذا مع العلم أن المصنف فقيه حنبلي، ومحدث أثري.

ج. اختلاف الأمة وسيرة الأئمة، وخخالفة الخلف للسلف الصالح في فهم الدين والعمل به، وما يجب أن يكون عليه المسلمون في دينهم وشرعهم.

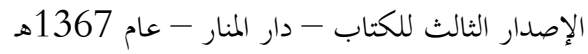
37 يعنى أقوال أئمة السلف وعلماء الأمصار من أصحاب المذاهب المختلفة وأدليتهم، أنظر مقدمة المغني، ص 1367 اهـ 13. 38 
لم يكن رشيد رضا متقيدا بمذهب فقهي معين، وإنا كان يجتهد بعمل شخصي، يفتي فيه بالدليل ويسلك فيه سبيل أهل الاجتهاد المطلق، لذلك جاء اجتهاده في ججال الأحكام متميزا لا سيما في تفسيره لآيات الأحكام في تفسيره المشهو ر بتفسير المنار، وهذه ملاحظات عامة عن اجتهاده في مجال النص:

$$
\text { أ. الفهم الجيد والحافظة القوية. }
$$

ب. الخبرة الجيدة بالواقع.

ج. الوعي العقلاني التام بالأحكام الشرعية.

د. المعرفة الجيدة لكيفية تنزيل الأحكام على وقائعها.

$$
\text { هـ الإدراك التام لمطامح الشعوب الإسلامية. }
$$

و و وضوح الرؤية وجودة الأسلوب وبلاغة العبارة.

ز. الخبرة بالمد والجزر في الممارسة السياسية.

ح. حسن تمرير الفكرة السياسية عبر العمل الصحافي الملتزم.

بهذا غدا رحمه الله موسوعة زمانه، وبجتهد عصره، وبجدد قرنه، ولم يحد عن السنة بل سار على طريق السلف في

$$
\text { تقرير الحق وتقعيد العلم وخدمة الشريعة الإسلامية. }
$$

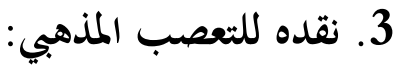

عرف رشيد رضا بنقده الصارم لمتعصبة المذاهب الفقهية، وقد أعانه على ذلك تتبعه الدقيق للعوامل والأسباب التي أوقعتهم في هذه الصفة، يدلنا على ذلك سرده لأحداث التعصب وما جنته على الأمة من جمود وتخلف وتمزق، سرد يصاحبه نقد منهجي ومضموني بلغة سهلة وواضحة لكنها من حيث القواعد اللغوية رصينة لا تخترق، يقول: "ولكن المتعصبين للمذاهب أبوا أن يكون الاختلاف رمة، وشدد كل منهم في تحتيم تقليد مذهبه، وعدم الترخيص للمنتمين إليه في تقليد غيره ولو لحاجة أوضرورة، وكان من مناظراتم في ذلك، ومن طعن بعضهم في بعض ما هو 
معروف في كتب التاريخ والتراجم وغيرها كالإحياء للغزالي"39 وهذا مخالف لوحدة الأمة الإسلامية التي أرادها الله أن

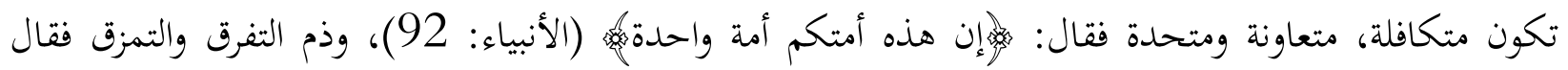
تعالى: هوإن الذين فرقوا دينهم وكانوا شيعا لست منهم في شيء (الأنعام: 159)، وإذا ما وقع الخلاف -وهو واقع لا محالة- فمرده إلى الوحي لأنه هو المعين الوحيد على حل الخلاف، قال تعالى: والرسول إن كنتم تؤمنون بالله واليوم الآخر، ذلك خير وأحسن تأويلاه内. (النساء: 59)، فهذه الاية هي شعار الوحدة، وميزان من يدعو إلى الوحدة، وهي أساس الائتلاف، وقاعدة في درء الاختلاف، يقول رضا: "حقا إنني على ضعفي وعجزي حريص على الإصلاح الإسلامي على إطلاقه وعمومه، ولا أخص به أهل مذهب دون غيره، وإني لست سنيا بمعنى التعصب، بل أنا سني بمعنى أنني مستمسك بما صح من سنة النبي صلى الله عليه وسلم لا أوثر عليه تقليد أحد".

وكان يوازن في نقده بين تعصب الخلف وتساهل السلف الصالح، هؤلاء الذين كان فقهاؤهم يأخذون بما أراده الله من اليسر في الشرع وانتفاء الحرج منه، وكانوا يضعون في سلم الأولويات عدم التفريق بين المسلمين بالظنون الاجتهادية "حتى كان أشهر الأئمة لا يستحلون الجزم بالحكم فيها، فيقول أحدهم: أكره كذا، أو: لا أستحسنه، ويقول في مقابل ذلك: يفعل السائل كذا احتياطا، أو : أحب كذا، أو : يعجبني، أو: أعجب إلي، أو: هذا أحسن، هكذا كان يقول الإمام أحمد في المسائل الاجتهادية أوفيما لا نص صحيحا صريحا فيه من الكتاب أوالسنة ويؤثر نحوه عن غيره".

وقد لا حظ رشيد رضا أن مدونة المذاهب جعلوا من كل هذه الاحتياطات قواعد لهم في تشريع الأحكام، ومع توالي الزمن خرج إلى الوجود فرق مستقلة في الفروع صارت فيما بعد -مع متكلمة المذاهب- فرق مستقلة في العقائد أيضا، وهذا كله بعيد عن وضع اجتهاد الأئمة، فالأئمة الكبار من أمثال أبي حنيفة النعمان بن ثابت (80 150ه)، 42 ومالك بن أنس الأصبحي (95 - 179هـ)، 43 ومحمد بن إدريس الثافعي (150 - 204هـ)

$$
\begin{aligned}
& 39 \\
& \text { 40 } 40 \\
& 41
\end{aligned}
$$

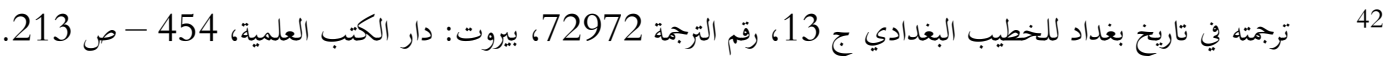

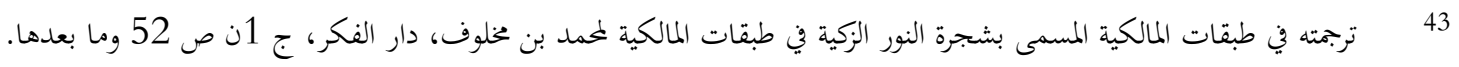


والإمام أحمد بن حنبل الشيباني (164 - 241هـ) إنما كانوا أئمة لجميع المسلمين، وذلك بتمسكهم بأصول الدين، وأخذهم للأحكام الشرعية بمأخذ الفهم من نصوص الكتاب والسنة، وما صح عن الصحابة، أما ما فعله تلامذقم وأصحاهم من جمع لاستنباطاقم واجتهاداقم فهو صيانة من الضياع، وهو مهم في فتح أبواب العلم، وتسهيله لطلبة العلم لا أن يجمدوا عليه، يقول ابوإبراهيم إسماعيل بن يهيى المزني 46 "اختصرت هذا الكتاب من علم حمد بن إدريس الشافعي رمه الله، ومن معنى قوله لأقر به على من أراده مع إعلامه غيه عن تقليده وتقليد غيره، لينظر فيه لدينه، ويختاط لنفسه".

إن الجمود على رأي الإمام واجتهاده وحده يجعل منه شارعا أو كالشارع، وهذا فيه ما فيه من مخالفة الشرع، ومن افتراق الطوائف المقلدة التي تتباين وتتعادى وتختلف وتتناقض، وقد اختلف المسلمون في أمور الشريعة اختلافات كثيرة، وتباينت آراؤهم، وتعددت مشاركم وتناقضت أحوالهم، وقد أفضى هذا الاختلاف إلى ظاهرة التكفير والتفسيق والتدجيل، وهي ظاهرة - للأسف الشديد- سرت في صفوف الدعاة والعاملين في الإصلاح حيث تبادلوا التهم التي كان علماء الأمة لا يطلقوها إلا في حق الفساق والفجار والمنافقين، ووصية رشيد رضا إلى هؤلاء هي أن يستلهموا من علماء الأمة وبجتهديها قوة علمهم وحسن فهمهم، ويتركوا تعصب المذاهب الفقهية التي ظهرت بعد موت الأئمة، تعصب تعددت آفاته: من أكبرها وأخطرها التفرق المذموم والتشتت المبغوض، فالاختلاف في الصف مثلاً هو اختلاف في الظواهر ولكنه يسري إلى الباطن فيغيره، فتنبثق من الداخل قناعات راسخة تصبح على مر الزمان قاعدة يبنى عليها عمل شاذ، وقدم رشيد رضا الدليل على ذلك من حديث النعمان بن بشير رضي الله عنه 48 مرفوعا: (لتسون صفوفكم أوليخالفن الله بين وجوهكم)، 49 والمخالفة بين الوجوه شرحها الإمام النووي 50 بأن الله يوقع بين

تربمته في تاريخ بغداد -ج 2، ص 56 وما بعدها ترمة رقم: 454 وطبقات الشافعية- لأبي بكر هداية الله الحسيني ص 11-12 - تعقيق

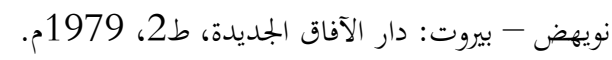

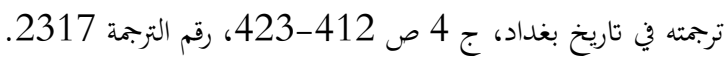
45

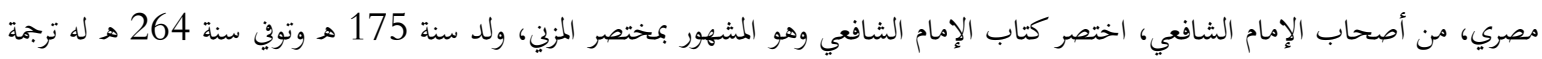
46

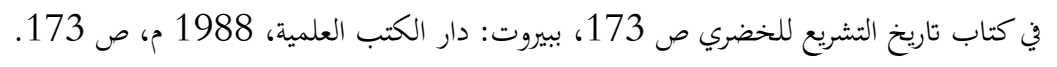
كختصر المزين، المقدمة، بيروت: دار المعرفة. 48 صحابي وابن صحابي، خزرجي أنصاري، مات سنة 65 هـ، له تربمة في تقريب التهذيب، للحافظ ابن حجر، رقم 7152، بيروت: مؤسسة

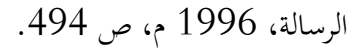
أخرجه البخاري في كتاب "الأذان" - باب: "تسوية الصفوف عند الإقامة"- فتح الباري: ج 2، ص 206-207، رقم الحديث 717 - طبعة

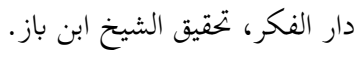


المخالفين العداوة والبغضاء ومخالفة القلوب، 51 وإذا اختلف القلب اختلف كل شيء52 وللحديث شاهد آخر عند أبي داود بلفظ: (والله لتقيمن صفوفكم أو ليخالفن الله بين قلوبكم) 53 وفي حديث آخر: (لا تختلفوا فتختلف قلوبكم)، 54 والمعنى الذي جاء في الحديث مؤيد من وجوه كثيرة، منها ما بينه رشيد رضا بقوله: "ويؤيد المعنى من المعقول والتجارب ما ثبت من الاتفاق في العادات واللباس من أسباب التآلف، والاختلاف فيها من أسباب التنافر فكيف إذا كان الخلاف في الدين، وكان كل فريق يعتقد أن الآخر مخالف لله ولرسوله بدعواه أن ما عليه أهل مذهبه هو الحق، وما خالفهم فيه غيرهم باطل". 55

ولما كان التفرق سببا في ذهاب سلطة الأمة، وسببا في إضعافها بين الأمم، وسببا في تمكين الأجانب من الاستيلاء على البلاد والعباد كانت النصيحة التي يقدمها رضا هي: "وجوب تلافي شرور هذا التفرق، وجمع الكلمة ووحدة الأمة، وكان هذا الغرض من أهم ما أنشأنا لأجله مجلتنا "المنار"، وأول ما كتبناه من التفصيل في ذلك "محاورات المصلح والمقلد" التي نشرت في المجلدين 3 و4 أي من أكثر من ربع قرن، ثم جمعت في كتاب مستقل منذ بضع عشرة سنة"، 56 وهذا الفعل من الشيخ رضا إنما يأتي من منطلق إيمانه أن الدعاة إلى الله والعاملين في الإصلاح العام مالوا إلى التيسير ساهموا في جمع الشمل ولم الصف، وكلما تشددوا وتعسروا كلما شقوا مع الأمة التي يعاني أهلها من الجهل الفظيع والتخلف المريب، وفي القرآن والسنة نصوص ذات أحكام شرعية تشهد لهذه الدعوى منها قوله تعالى: >ولفما رحمة من الله لنت لهم ولو كنت فظا غليظ القلب لانفضوا من حولك (آل عمران: 159)، وفي

وأخرجه مسلم في صحيحه - كتاب" الصلاة"- باب "تسوية الصفوف وإقامتها"، ج 1 ص 324، رقم الحديث 436، مطبعة دار إحياء الكتب

$$
\text { العربية، بعناية محمد فؤاد عبد الباقي. }
$$

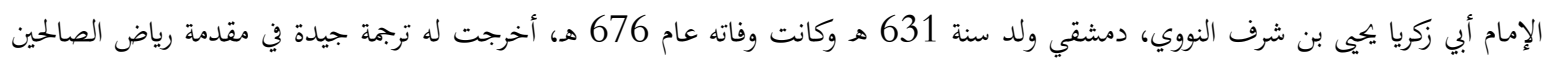

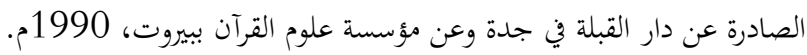

$$
\begin{aligned}
& \text { استفيد هذا التعليق من هامش رقم (01) في صفحة } 324 \text { من صن صحيح مسلم. }
\end{aligned}
$$

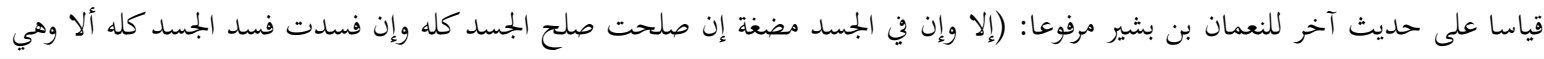
52

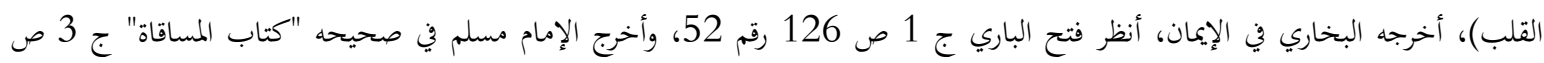

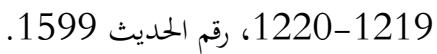

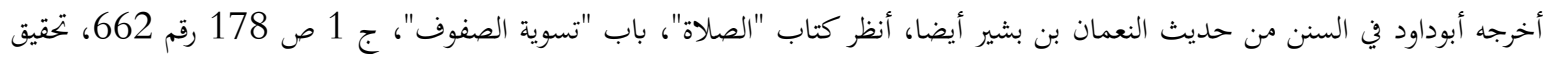

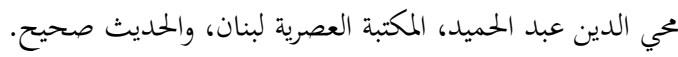

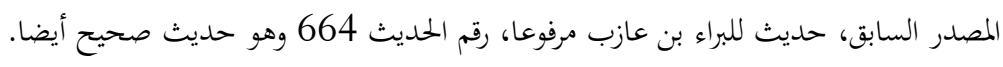
54 مقدمة المغني ص 16. 55 المصدر السابق، وهو يريد بذلك كتاب: الوحدة الإسلامية والوحدة الدينية، سبقت الإشارة إليه. 
حديث أبي موسى الأشعري 57 مرفوعا: (يسروا ولا تعسروا، وبشروا ولا تنفروا) 58 وفي حديث أبي هريرة 59 مرفوعا: (إن الدين يسر، ولن يشاد الدين أحد إلا غلبه، فسددوا وقاربوا وأبشروا)، 60 وهذا كله لغرض واحد كان الشيخ يريد كشفه للناس وبيانه لهم وهو الذي يقول فيه: "وإنما غرضنا هنا أن نبين أن يسر الشريعة وحكمة التشريع، 61 وكون الاجتهاد رممة للأمة إنا يعرف من مجموع كلام المجتهدين، ويفوت من قصر نظره على مذهب واحد من مذاهبهم، وأن طلاب الإصلاح للأمة الإسلامية ما زالوا يقترحون تأليف جمعية من علماء المذاهب المتبعة كلها تضع للأمة كتبا في العبادات والمعاملات تؤخذ من نصوص الكتاب والسنة، ومن اجتهاد جميع المجتهدين، يراعى فيها اليسر ورفع الحرج ودرء المفاسد ومراعاة العرف، وغير ذلك من القواعد.62

\section{4. - دعوته إلى وحدة المذهبين: السني والشيعي}

الدعوة إلى الوحدة هي دعوة عامة عند رضا، والوحدة في دعوته وحدة شاملة، فلم تقتصر على وحدة المذاهب الفقهية عند أهل السنة فحسب بل دعا إلى الوحدة بين المذهبين السني والشيعي، غير أن الدعوة لم تكن تتغاضى عن العيوب القائمة بين اتباع المذهبين ولا تحجب عنه رؤية البدع والمنكرات الواقعة فيهم، فقد نال المذهب الشيعي من نقده ما نال مذهب أهل السنة، ومن خلال النقد كان يبين أن مسائل خلاف المذهبين إنما تزيد في الفرقة وفي التشتت، وأن اجتهادات مجتهدي أصحاب المذهبين لا تساهم في الوحدة، وفي قوله تعالى: ولغرإن الذين فرقوا دينهم وكانوا شيعا لست منهم في شيءمه. (الأنعام: 159) وعيد لمن فرق الدين بأي شكل من الأشكال، وما كانت الوحدة من الفروض المطلوبة شرعا اهتم بها اهتماما بالغا، وقد شكل موضوع الوحدة بين السنة والشيعة حيزا كبيرا من

عبد الله بن قيس بن سليم، صحابي مشهور، أمره عمر ثم عثمان، وهو أحد الحكمين بصغين، مات سنة: 50هـ، وقيل بعلدها، ترجمته في "تقريب

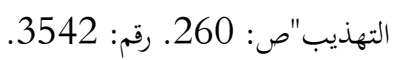

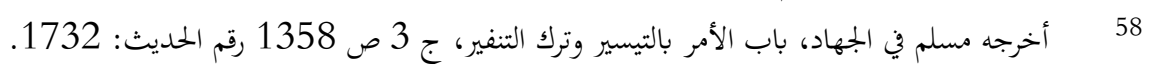

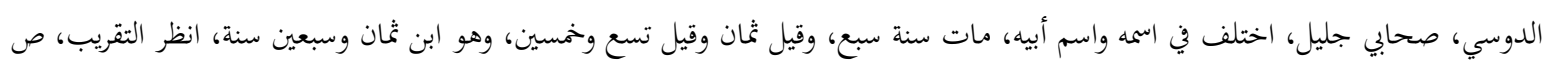

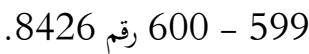

$$
60
$$

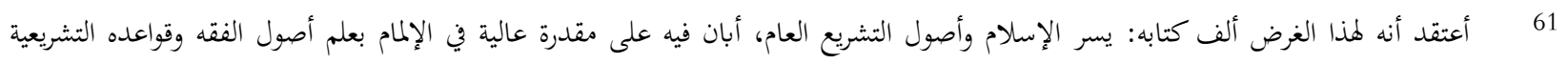

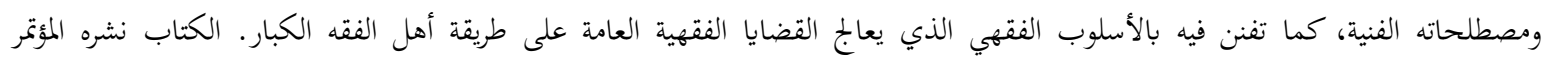

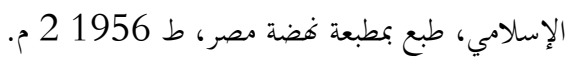
مقدمة المغني، ص 23. 
جهده وعمره فقد جاهد في سبيل ذلك أكثر من ثلث قرن كما ذكر ذلك بنفسه، 63 ومهما كان الخلاف طاغيا ومتأصلا تاريخيا فإن قاعدة رشيد رضا في الوحدة هي قوله: "أن نتعاون على ما نتفق عليه، ويعذر بعضنا بعضا فيما نتخلف فيه"،64 ويخاطب السنة والشيعة جميعا فيدعوهم إلى ضرورة التوحد بعبارة جامعة مانعة يقول فيها: "إذا كنا لسنا في حاجة إلى الانتقام، وإذا كنا قد ذقنا فعرفنا جناية سل الحسام، وإذا كنا مهددين في كل أرض لأن ديننا الإسلام، وإذا كنا - كما نعلم- على خطر لا ينجي منه إلا الاتحاد والالتئام، وإذا كان هذا الاتحاد متعذرا من جهة وحدة السلطة والأحكام، أفلا يجب علينا أن نتلمسه من جهة الوحدة الدينية في العقائد المتفق عليها، والأخلاق التي لا خلاف فيها، والأخوة التي دعانا القرآن إليها، أفلا ينبغي أن نأخذ هذه المواسم مذكرات بأفضل ما كان من سلفنا، وأنفع ما كان من أئمتنا، ونجتهد في أن نجعل شعورنا واحدا حتى يصدق علينا قول نبينا صلى الله عليه وسلم: (ترى المؤمنين في تراحمهم وتوادهم وتعاطفهم كمثل الجسد إذا اشتكى منه عضوتداعى له سائر جسده بالسهر والحمى)

\section{خامسا: شمولية الإصلاح السياسي عند الشيخ رضا.}

كلمة الإصلاح التي نتكلم عنها هي كلمة عامة وشاملة، فهي لا تنحصر في جزئية من جزئيات الحياة، ولا في مكون من مكونات المجتمع، والسعي بها في الحياة يقتضي إصلاح المؤسسات الفكرية والاجتماعية من هنا تنبثق النظرة الإصلاحية للرجل، وإذا أردنا فهم الإصلاح لديه وجب استحضار الأزمة العامة والمشكلات الشاملة التي خيمت بكلكلها على العالم الإسلامي برمته، لقد ساهم أولئك الأعلام -ومنهم رضا- في التخفيف من حدة وطأة المشكلات والأزمات التي بلغت حدتا الغاية وذلك بتشخيصهم لما، واقتراح حلول لمعالجتها، ولم لا: فقد ساهموا في إزالة بعضها، واعتقد أنه لولا جهودهم الموفقة لكانت الأزمات والمشكلات أكبر بكثير مما هي عليه اليوم، إذم وقفوا وراء صيحات التحرر، وتقيق الانفصال عن الحكومة الاتحادية في تركيا، وطرد الاستعمار من ديار المسلمين بل يكفيهم فخرا أفم يقفون وراء موجة الصحوة الإسلامية التي تعم العالم الإسلامي اليوم. هذا ويجدر بدعاة الصحوة أن

$$
\text { } 63
$$

64 64

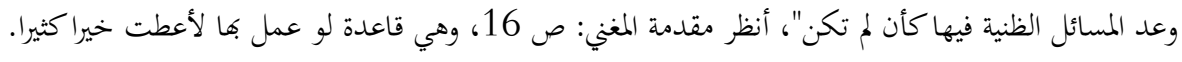

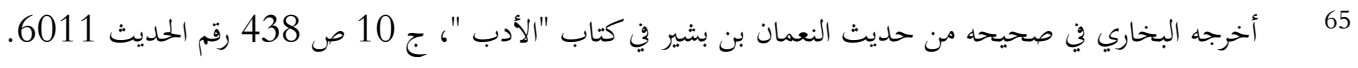

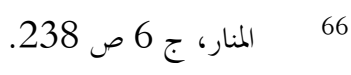


يقفوا على حقيقة الدعوات الإصلاحية عند هؤلاء الأعلام، لأن هؤلاء لم يكونوا يعملون لأنفسهم ولا لأوطاهم إفم كانوا يمسون الكيان الإسلامي برمته، والضمير الإسلامي الحي أينما كان، ونظن أن سبب فشل بتارب المعاصرين في بجال الإصلاح السياسي إنما يكمن في عدم استقراء التجارب المماثلة، والجهو د السابقة التي لا تبعد عصرا ولا وطنا. إن كثيرا من الآراء التي جاء بها رشيد رضا هي في حاجة إلى بحث وتفصيل على المستوى السياسي، وذلك أن أفكاره في مجال الإصلاح تبدو صالحة لكثير من مشكلات هذا العصر، نذكر منها مثلا: أ. تحرير العقل من الأوهام والخرافات والشعوذة، وتنويره بالفكر العلمي والتقدمي.

ب. محاربة الشرك وعبادة الأوثان والقبور بالدعوة إلى التوحيد والربوبية الحقة. ج. محاربة الجمود والتقليد والكسل وذلك بتفعيل الاجتهاد والفهم السليم للنص. د. مناهضة الظلم والاستبداد والقهر بالعدل والشورى والتسامح. ها. الدعوة إلى العلم والتقنية الاختبارية، وإشاعة روحها في المجتمع الإسلامي. و. الدعوة إلى الصناعة الفاعلة، والتجارة الرابحة، والفلاحة الناجحة. ز. إصلاح كل أمراض المجتمع التي تفتك به فتكا كالرشوة والزنا والقمار والربا والانتهازية ... ط. محاربة الاستعمار بمختلف أشكاله، وبث الوعي السياسي الشرعي في الأمة. كل هذه هي دعوات ومطالب كان رشيد رضا يتحرك في إطارها وما لم نذكره بالاسم فهو يدخل في عمومها. إن الإصلاح الذي يريده رضا هو الإصلاح السياسي الذي يتم بالإسلام ويف الإسلام، وقد يعتقد البعض أن أحسن إصلاح هو الإصلاح الذي يكون على حساب الشريعة الإسلامية وذلك حين يجمعون بينها وبين ما خالفها من القوانين الوضعية والأحكام العلمانية، فالشريعة في نظره تحوي أصولا جامعة، صالحة لأي إنسان كان في أي زمان ومكان، جاءت لتعتق الإنسان من العبودية والظلم، وتحره من الخرافات والأوهام والشرك، وبما أها آخر الشرائع السماوية على الإطلاق فإنه لا يقبل من أي كان أن يبلغ شيئا باسم الوحي، فيشرع تحريما وتحليلا باسم الدين، 
والحكومة التي تنشأ في المجتمع الإسلامي والتي تسهر على مصالح المسلمين إنما هي حكومة مقيدة بالأحكام الشرعية التي تضبط العدل والشورى، وليس لأي كان أن يستبد بالتفسير والتحليل باسم السلطة الدينية الروحية، فليست في الإسلام سلطة دينية روحية، إنما تستنبط الأحكام بالعلم والفهم وفي استقلالية تامة، وهي تتأتى لكل من آنس من نفسه قدرة على الاستباط وتحلى بالشروط التي قررها أهل هذا العلم لهذا الغرض، لذلك فالعلماء المجتهدون هم سواسية في جميع أحكام الشرع، وإنما يتفاضلون بتفاوتم العلمي والعملي، ويتفقون جميعا على أن الأحكام السياسية والمدنية إنما تستند على قاعدة: درء المفاسد وحفظ المصالح والحرص على الضرورات الخمس التي أقرها أهل الأصول والفقه والمقاصد. 67

\section{سادسا: السياسة العامة عند رضا.}

نظر رشيد في الصفحة السياسية العالمية والمحلية من منظور الشريعة الإسلامية، فانتصر للحق ودعى إلى الوحدة الإسلامية ورد على الظالمين والمستبدين والملحدين، وأبدع في الممارسة السياسية الإسلامية بخاصية التوازن في العمل السياسي، ومن منطلق نظرته المتوازنة التي أكسبته تماسكا في اتخاذ الموقف سنسلط الضوء على بعض مواقفه من السياسة العامة، وذلك بتقسيمها إلى سياستين: خارجية وداخلية.

أ. موازنته في مجال السياسة الخارجية: وقف رشيد رضا -وهو يعالج القضايا السياسية الخارجية- أمام كتلتين: إحداهما قائمة، صامدة لكنها تعيش مخاضا من الداخل، والثانية تبدت كقوة جديدة، هاجمة، تريد ابتلاع الأولى وانتزاع السيادة منها، فالأولى هي قوة الدولة العثمانية والثانية هي القوى الغربية. كيف كان موقفه منهما؟

لا يمكننا الحديث عن موقف واحد موحد في مجال السياسة، لأن عالم السياسة هو عالم متغير، وطبعي جدا أن تتغير المواقف وتتبدل الأقوال، ولقد حاول بعض الباحثين أن يهكموا على الشيخ بالتناقض والاضطراب وهم يعلمون جيدا أن بين القولين الموصوفين بالتناقض فسحة من الزمن، وهذه الفسحة كفيلة بأن تتغير فيها أشياء كثيرة، ففي 30 كانون الثاني من عام 1923م كتب رشيد رضا رسالة إلى أمير البيان شكيب أرسلان 68 يذكر له فيها أنه يرجح الترك

$$
\text { } 67
$$

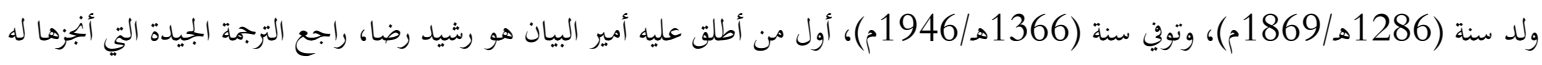


على الإفرنج على سلبياتم في ظلم العرب واحتقارهم والبغاء عليهم، وكان يطلب أن يعود الترك لحكمهم للبلاد العربية عوض بقاء الإفرنج فيها، 69 وهذا الموقف هو الموقف الأصيل لرشيد رضا وهو الموقف الشرعي الذي أصله بمبررات كثيرة منها أن وجود الإفرنج في ديار المسلمين هو كارثة حقيقية لمدم الأخلاق والعلم والتربية ومصادرة الشخصية المسلمة، يضاف إلى هذا انعدام التجاوب بين أهل البلد والمستعمرين، وإذا اختار الأتراك فلدواع كثيرة منها القواسم المشتركة الكبيرة بين العرب والترك، ثم إن حكم الأتراك هو حكم عريق في هذه البلاد ألفه الناس وعاشوا عليه.... لكن بعد ثلاثة سنوات من تاريخ الرسالة الأولى وبالتحديد في سنة 1926م كتب رسالة أخرى لشكيب أرسلان يذكر له فيها أنه لم يعد مرتاحا للحكم التركي لا سيما بعد أن ظهرت نوايا مصطفى كمال أتاتورك في تثبيت دعائم العلمانية في كل مؤسسات الدولة بعد أن ظهر خطه المعادي للإسلام جهارا، لقد أعرب في هذه الرسالة السياسية أنه بدأ يرى في التسلط التركي على ديار العرب خطرا هو أشد من خطر الإفرنج، 70 وأعتقد أن رشيد رضا وازن بين وقوع نظام الحكم في تركيا تحت السياسة الغربية وبين وقوع بلاد العرب تحت حكم الأتراك إذ سيعاني العرب في هذه الحالة من ظلمين مركبين: ظلم الأتراك وظلم الاستعمار، فكان لا بد من اختيار ضرر واحد هو ضرر الاستعمار وحده، وهو الضرر المرجح، لكن كان أمامه اختيار آخر هو بحث العرب عن أنفسهم، وتكوين دولتهم المستقلة، دولة عربية قوية، قادرة على حكم نفسها بنفسها بعد إجلاء الاستعمار عنها وهذا ما سنراه في حديثنا عن السياسة الداخلية.

ب. موازناته في مجال السياسة الداخلية: السياسة تحتاج إلى الأخلاق لأن الأخلاق تحافظ على التماسك الفكري، وعلى التوازن التام في اتخاذ المواقف من الأحداث الجارية، واعتقد أن رضا كان على هذه الخصال، فقد حافظ على تماسكه الفكري وتوازنه في التعبير عن مواقفه حيال الأحداث، إذا مال إلى حركة سياسية معينة برر هذا الميول، وإذا تخلى عنها ومال إلى ضدها برر أيضا، وفي كلتا الحالتين كان يؤصل آراءه بالشرع، ويستخدم القواعد اللازمة في الترجيح والموازنة، لقد وجد نفسه بين حكومتين متصارعتين يراد لواحدة منهما أن تكون لها السيادة على كلى أرض الحجاز، وتمثل الحكومة الإسلامية المرتقبة التي كان ينتظرها بشغف كبير، الأولى هي حكومة الحجاز بزعامة الشريف حسين شريف مكة والثانية حكومة نجد بزعامة آل سعود، ولم يتمكن رضا من اتخاذ موقف مؤيد أو معارض لما يجري بينهما من خلاف إلا بعد أن سبر وضعيتهما، وتعرف على مقاصدهما وصحة ادعاءاتما التي من أبرزها:

$$
\begin{aligned}
69 & \\
&
\end{aligned}
$$


خدمة الإسلام والمسلمين وصيانة الديار المقدسة، وفي المنار نجده يبسط لنفسه وللناس موازنة بين الحركتين يستخلص منها ما يبرر ميوله لإحدى الطائفتين. 71

مهما تقلبت الأحداث وتغيرت الظروف فإن رضا كان حاضرا بقلبه وعقله، يصوغ ما يجري بقلمه، يسعى من خلال كتاباته النقدية والتقويمية إلى التأثير في الأحداث، وعوض أن يقف موقفا متفرجا كان ينخرط فيها ويوجه ما يراه صائبا وصالحا للبلاد والعباد، وكان هاجسه السياسي هو البحث عن الدولة الإسلامية التي تجمع شتات المسلمين، وتحافظ على التوازن في المنطقة.

تلك هي ملامح عن السياسة العامة عند رشيد رضا، سياسة ذات بعدين: خارجي وداخلي.

\section{سابعا: الموضوعات السياسية التي تكلم فيها}

نعني بذلك الموضوعات السياسية التي تكلم فيها من منظور السياسة الشرعية، وقد اخترنا لها موضوعات الخلافة والشورى والثورة والاشتراكية.

موضوع الخلافة: كتب رشيد رضا في موضوع الخلافة، وأصدر فيها كتابا بعنوان: "الخلافة أوالإمامة العظمى"، 72 ومعلوم أن موضوع الخلافة هو من الكلام المخظور تداوله في ذلك العصر لدرجة أنه كان من الموضوعات الممنوعة على طلاب الإصلاح من العرب، والسبب أن حكومة الأستانة كانت تراقب كل المطبوعات، وتمنع نشر كل كتاب من كتب الكلام والعقائد والحديث والتفسير التي تذكر فيها قضية الخلافة، حتى أن المطابع كانت تحذف الفصول والأبواب التي تتكلم في الموضوع إن أريد لمذه الكتب أن تروج في عاصمة الدولة، 73 لكن ما شأن رشيد رضا بكومة الأستانة، فالسلطان عبد الحميد لم يعد له من الأمر شيء إلا الاسم، وأن الأمر قد استتب في يد الاتحاديين، وأن القرار السياسي أصبح قبضة في يدهم، أما الشعب الذي هو في حاجة إلى خطابات سياسية في موضوع الخلافة هو الشعب العربي، وأن لرشيد رضا منبرا خاصا يخاطب من خلاله العرب غير أنه كان يعين المجلة بمؤلفات مستقلة

$$
\begin{aligned}
& 71 \text { والواضح أنه رجح حكومة نجد على حكومة شريف مكة، انظر بسط ذلك في المنار، المجلد } 26 \text {-ج } 6 \text { ص 454-477، } \\
& 72 \\
& 73
\end{aligned}
$$


تتصل بالموضوع رأسا، منها كتابه "عمد رسول الله"74 ثم كتابه "أبوبكر الصديق أول الخلفاء الراشدين"، ثم أردفه بمصنف حول عمر بن الخطاب وعثمان بن عفان وعلي بن أبي طالب والحسن والحسين، وهي مطبوعة ومتداولة. 75

إن تجرد محمد رشيد رضا للتأليف في صدر الإسلام ابتداء من عهد النبي صلى الله عليه وسلم إلى عهد الحسن والحسين ليدل على أنه وضع يديه على القلب في قضية الخلافة، فالأحداث التي وقعت على عهد رسول الله والخلفاء الراشدين والحسن والحسين هي أم أحداث الخلافة الإسلامية والأزمنة التي عاشوا فيها هي الأزمنة المفضلة والمباركة في زمن الخلافة الإسلامية، والأمكنة التي عاشوا وماتوا فيها هي الأمكنة المقدسة التي تحظى باهتمام المسلمين ورعايتهم حتى أن حركة الانفصال عن الإمبراطورية العثمانية إنما ظهرت في الحجاز، أما فتاواهم وأحكامهم واجتهاداقم وأقضيتهم وما خلفوه للأمة من سنن فهو زاد لكل من يتولى الخلافة أو يعمل باسمها، لكن الحكمة من هذا كله هو تذكير المسلمين بحياة الخلفاء والأبطال السياسيين المخلصين لأحكام الشريعة الإسلامية لتبقى حية في الأسفار والقلوب، وحاول رضا -بقدر ما أوتي من علم وفهم وتدقيق- أن يصور شخصياقم بصورة جلية واضحة، تبقى حية ماثلة أمامهم في أي عصر، وباعثة لمهم، وقدوة يحتذي بها الأبناء في حسن البلاء، طلبا للإقدام، ودرءا للتولي والإحجام، رفعة للشأن، ورغبة في الصبر والإخلاص، ذلك أن نشر التوحيد والعقيدة الصحيحة يحتاج إلى التضحيات الجسام، والقضاء على الوثنية والشرك يتطلب العزيمة والهمة، أما نشر العدل والفضل فلابد لما من الإيمان الراسخ والوجدان الصافي.

موضوع الشورى: الشورى هي عصب الحكم، وشريان العدالة في الإسلام، لا يستقيم الحكم إلا بها، لذلك أولاها رشيد رضا أهمية بالغة في مقالاته، ولقد لقيت نظرياته في مجال الشورى قبولا واسعا لاستهدافها محاربة الاستبداد الفردي الذي يسود نظم الحكم في الأقطار العربية التي تعيش تحت ظل الإمبراطورية العثمانية، ومما يدل على أن آراءه في مجال الشورى انتشرت بصورة كبيرة جعلت الدولة العثمانية تقف ضده متخذة في ذلك إجراءات صارمة، منها: منعه من الوصول إلى الأراضي العربية التي كانت خاضعة لحكمها، ومضايقة إخوة رشيد رضا في القلمون، وحاول جواسيسها تخريب مكاتب المنار في القاهرة.

74

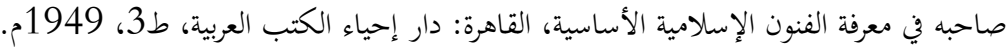

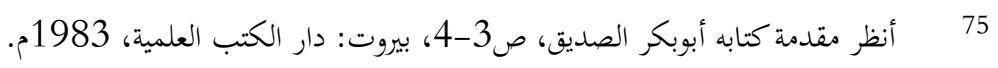


وقد استمرت هذه المضايقات على رشيد رضا وأسرته حتى إعلان الدستور عام 1326هـ الموافق لعام

وبالروح نفسها انخرط رشيد رضا في أول حزب سياسي أسس في مصر اتخذ له اسم حزب الاتحاد الشوري، وكان واحدا من مؤسسيه، والغرض من وجوده فيه هو تبليغ فكرة الشورى إلى الشعب، وتعليمها إياهم، أما انخراطه في الحزب فيدل على محاولة ممارسة السياسة بطريقة شورية، لكن الحزب لم يذهب بعيدا لأنه كان يضم بين جناحيه فرقتين مختلفتين: فرقة من الاستقلاليين الذين يطالبون بالاستقلال التام عن الدولة العثمانية، وفرقة من الاحتلاليين الذين يرون بأن الاستقلال إنما ينبني على مساعدة أجنبية تعلم الشعب الحكم الديموقراطي النيابي وتقوده نخو العدالة، ورضي هذذا الاختلاف والتناقض لأن فكرته كانت ناصعة وواضحة جعلت أكثر نصارى العرب ينسحبون من الحزب. 77 ولما ظهرت حركة تركيا الفتاة التي قادتا جمعية الاتحاد والترقي، واتسع صداها في الخارج، وأصبحت لها فروع تابعة بادر رشيد رضا بتأسيس جمعية تدعى جمعية الشورى العثمانية ردا على علمانيتها وتحللها وإهانتها للعرب والإسلام، وقد مكنته هذه الجمعية من إصدار مقالات في الحكم الاستبدادي المطلق وما جناه على الأمة، وملا بشر الانقلابيون بالحياة الدستورية كتب رشيد رضا مقالات كثيرة يهلل فيها بالدستور، ويعد الأمة بغد سياسي أفضل، وألقى خطبا كثيرة في هذا الشأن معتبرا أن يوم إعلان الدستور هو يوم عيد للأمة، وأنه نعمة من نعم الله على المسلمين، وقد أضفى عليه رضا طابع الشرعية حين قارنه مع نظام الشورى الإسلامي، فالدستور يشبه نظام الشورى لأنه يحد من نظام الحكم الاستبدادي، ويلغي نظام الحكم المطلق، يقول: "إن القوم الذين يرضون أن يستبدهم حاكم يفعل فيهم ما يشاء، ويحكم بما يريد ينبغي أن يعدوا من الدواب الراعية، والأنعام السائمة". 78

ولا يشك رشيد رضا في أن مقاومة الاستبداد وإنشاء المجالس النيابية والدعوة إلى تحكيم الشورى وحكم العدل إنما هي أمور استفادها أهل مصر من معطيات ثلاثة: الأول: الإسلام وشريعته السمحة، فنصوصه وتاريخه حافل بالتجارب والأحكام الحاثة على ذلك.

$$
\begin{array}{r}
76 \\
78
\end{array}
$$


الثاني: عالمان جليلان، كان لمما دور كبير في تحريك النظرية السياسية الإسلامية بصفة عامة، ونظام الشورى بصفة خاصة في أنحاء العالم الإسلامي، وهما: جمال الدين الأفغاني ومحمد عبده.

الثالث: الاختلاط بالأوربيين، فلولا الاختلاط بكم لما تنبه المسلمون إلى حالهم، فإذا كان الأفغاني وعبده قد أتيا بما عجزت الأوائل عن الإتيان بمثله فإن الشعوب الإسلامية كلها تنبهت على اختلاف ابتاهاتها إلى خطر الاستبداد عليها، وسوء العاقبة التي تجنى من الحكم المطلق فالاستعمار له دور الموقظ والمنبه من الغفلة العظيمة التي أصابت المسلمين.

الثورة: بقدر ما كان جمال الدين الأفغاني (ثوريا) "يرى الثورة هي الوسيلة الأجدى والأفعل لبلوغ الغاية التي حددها كإستراتيجية لشعوب الشرق في ذلك الحين"، وبقدر ما كان محمد عبده (إصلاحيا) "يرى أن التدرج في الإصلاح هو الطريق الأقوم والأضمن في تحقيق هذه الغاية، وأن التربية المستندة إلى الدين بعد بتحيده بواسطة المؤسسات التربوية الجديدة وكذلك المؤسسات العتيقة بعد إصلاحها هي السبيل الوحيد لبلوغ غاية الشرق في التحرر الفكري والتحرير السياسي" 80 كان رضا يجمع بين الثورة والإصلاح فيما يمكن أن نسميه بالإصلاح الثوري أوالدعوة إلى "الثورة الإصلاحية" لأن الثورة والإصلاح في نظره أمران متلازمان لا يتحقق الهدف إلا بهما، جاء ذلك نتيجة جمعه بين أسلوب شيخيه، كما أن واقع المرحلة لا يسمح سوى بالجمع بين هذين الأسلوبين، لأغما عنصران فاعلان في التغيير السياسي الذي كان رضا يطمح إليه، ومن خلال مقالاته التي مارس في بعضها تحريضات سياسية قوية ضد الاتحاديين الأتراك المستبدين من جهة، وضد ثورة شريف مكة، وضد الاستعمار بكل صوره وأشكاله، وضد القوميين المسيحيين المطالبين بالوصاية الفرنسية أو الإنجليزية أو الأمريكية تظهر ثوريته جلية وواضحة، لكنها ليست ثورة جارفة، ساخطة على الوضع سخطا تاما كما كان حالها عند الأفغاني، بل هي ثورة من النوع المستساغ، إنه يثور بالمعالجة الهادئة، وبالتقويم الرصين، وبالإصلاح المتين الذي يدعو إلى تغيير الوضع من حال الظلم إلى حال العدل، ومن حال الاستبداد إلى حال الشورى والديموقراطية، ومن حال التمزق والتشرذم إلى حال الوفاق والاتحاد والتآخي، ومن حال الجهل والتخلف إلى حال العلم والتقدم والمدنية... هكذا تكون الثورة واضحة... ويكون التغيير الذي يرمي إلى

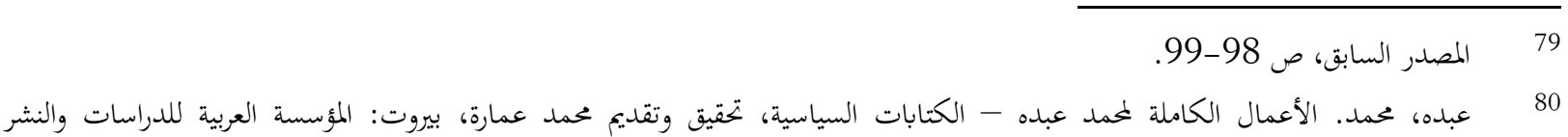
1972م، ص 37. 
تحقيقه بها إيجابيا ومقبولا، فالأزمة كانت عامة وشاملة، والأحداث تتوالد بكيفية فجائية وسريعة.... وهذه كلها تدفعه إلى المساهمة في تغييرها بما يراه ملائما.

نعود هنا إلى صلة الثورة بالشعب حيث نلاحظ أن الأفغاني كان يثق بالجماهير والعامة وحدهم دون غيرهم، لأن هؤلاء -حسب تصوره- هم أداة التغيير، وهم المالكون للقدرات الخارقة والضرورية التي يتوقف عليها قلب الوضع، أما محمد عبده فإنه كان قليل الثقة بالجمهور، ولا يراهن عليه كثيرا في التغيير، لأن عبده يدعو إلى منطق آخر يختلف عن منطق الثورة عند الأفغاني، وذلك من منطلق إصلاحي يركز على الذات الملقية، الذات التي تؤمن بأها هي المحرك لأحداث التغيير، لذلك أسقط عبده من حسابه الجمهور 81 ولا سيما في المرحلة الأخيرة التي ترك فيها السياسة، وقد تركها لتلميذه رشيد رضا الذي شرع فيها مباشرة بعد وفاة الأستاذ الإمام.

إن الجمهور الذي تركه عبده هو المجال الذي تحرك فيه رضا، وقد تحرك فيه بطريقة إيجابية وفاعلة بمجلة المنار التي خاطب بها الشعوب قاطبة بلسان العلم والوعي والفهم والثورة والإصلاح والتربية... فالمنار هي بجلة ثورية سياسية اقتصادية ثقافية اجتماعية فكرية وعلمية، وكان الخطاب السياسي هو ابرز خطاب يمكن للمرء أن يتلذذ بثمراته في المنار، خطاب سياسي ثوري على طريقة أهل الفقه الشرعي، يقارب ويسدد، ويوازن ويمهد، إذا ظهر له أن هذه الجهة هي أقرب إلى التأييد والمناصرة فعل، وكان يعدل عن رأي قاله بالأمس إلى رأي رأى صوابه اليوم، وتدلنا خطبه السياسية82 على أنه كان في معترك الوقائع السياسية الحساسة، وفي مواقع الثورة والتغيير، مصاحبا للثوار وناصحا وموجها ومرشدا.

الاشتراكية: عاصر رشيد رضا ظهو ر الثورة الاشتراكية الشيوعية في روسيا عام 1917م، وعاث امتداد شعارات هذه الثورة ومبادئها إلى العالم الإسلامي، وبدأت تتكون "قومية عربية اشتراكية" جديدة ترفع لواء الاشتراكية في العالم العربي والإسلامي، وتدين بالولاء لمفاهيم الثورة ولمبادئها، لم يقتنع رشيد رضا بالضجة النقدية التي أثيرت ضد الاشتراكية، وهي الضجة التي قادتا الدول الأوربية الرأسمالية الخائفة من المد الاشتراكي والشيوعي الذي يعطل مصالحها في المنطقة، وقادتا أيضا كل من الطبقة الأرستقراطية في روسيا الوفية للنظام القيصري المنهار، والطبقة الغنية

$$
\begin{aligned}
& 81 \\
& \text { راجع على سبيل المثال مختارات سياسية من مجلة المنار، ص } 133 \text { و 231-238، }
\end{aligned}
$$


المتحكمة في السلطة في البلاد العربية، أدار رشيد رضا وجهه عن كل هذه الاتمامات، وبادر إلى البحث والمطالعة وتقصي حقائق الاشتراكية بنفسه فوقف على حقائق عدة، منها أن المبادئ والحقوق التي نادت بها الاشتراكية كثير منها موجود في الشريعة الإسلامية، ولو عاد عقلاء هذا المذهب إلى الإسلام لوقفوا على قضايا كثيرة هي من عين ما يدعون إليه، كما أفم سيقفون على أمور كثيرة لم تخطر لهم على بال، لأجل ذلك خاض في مناقشة مبادئ الاشتراكية ودعوةها إلى سعادة البشرية، غير أن تحليلاته النظرية للاشتراكية كانت مصحوبة ببنود الشريعة الإسلامية، وكانت رؤيته إليها تتم وفق معطيات السياسة الشرعية وأصولها.

إن تطبيق السياسة الاشتراكية أوتطبيق أي مذهب آخر إنما الغرض منه هو تحقيق سعادة الأمة، لكن للأمة مقومات عقدية وروحية ولها تقاليد وأعراف وعادات هي من عين هذه العقيدة، ولن تكتمل سعادما إلا بسيادة هذه العقيدة المتمثلة في السياسة الشرعية التي جاء بها الإسلام، زد على هذا أن كل ما يمكن أن يتصوره الإنسان من الأمور التي توفر السعادة للإنسان خارج الإسلام هو موجود في الإسلام، وهذا ما اعترف به غير واحد من الغربين، فقد ذكر رشيد رضا في المنار أن ليون روش -وهو سياسي فرنسي- اعتنق الإسلام لأنه وجده يدعو إلى الاشتراكية والعدالة الاجتماعية، وذلك في فرضه للزكاة على كل ذي مال حيث أباح للفقراء حق أخذها غصبا إذا رفض الأغنياء دفعها طوعا.

خاتمة:

هذه ملامح عامة عن الإصلاح السياسي الشرعي عند الشيخ محمد رشيد رضا حاولنا من خلالها أن نكشف عن المؤهلات التي ساعدته على طرق باب الإصلاح، وكذلك الوسائل والطرق المختلفة لبلوغ هذا الإصلاح، وهي نظرات عامة حددت موقعه من الظاهرة الإصلاحية التي عرفها عصره السياسي، وأبانت عن عمق فهمه للفقه السياسي وإدراك سبل إصلاح القضايا العامة للأمة من خلالها، وذلك برؤية اجتهادية تستخدم الأوجه العلمية والفنية الموضوعة لمذا الغرض، رؤية إيجابية تبنى على الفهم الشمولي والنظرة الموسوعية والأسلوب الجيد والمعالجة المرنة. 